\title{
Active Management of Flap-Edge Trailing Vortices*
}

\author{
David Greenblatt \\ Technion - Israel Institute of Technology, Haifa, Israel \\ Chung-Sheng $\mathrm{YaO}^{\dagger}$ \\ NASA Langley Research Center, Hampton VA, USA \\ Stefan Vey, ${ }^{\ddagger}$ Oliver C. Paschereit \\ Berlin University of Technology, Berlin, Germany \\ Robert Meyer $\S$ \\ German Aerospace Center (DLR), Berlin, Germany
}

\begin{abstract}
The vortex hazard produced by large airliners and increasingly larger airliners entering service, combined with projected rapid increases in the demand for air transportation, is expected to act as a major impediment to increased air traffic capacity. Significant reduction in the vortex hazard is possible, however, by employing active vortex alleviation techniques that reduce the wake severity by dynamically modifying its vortex characteristics, providing that the techniques do not degrade performance or compromise safety and ride quality. With this as background, a series of experiments were performed, initially at NASA Langley Research Center and subsequently at the Berlin University of Technology in collaboration with the German Aerospace Center. The investigations demonstrated the basic mechanism for managing trailing vortices using retrofitted devices that are decoupled from conventional control surfaces. The basic premise for managing vortices advanced here is rooted in the erstwhile forgotten hypothesis of Albert Betz, as extended and verified ingeniously by Coleman duPont Donaldson and his collaborators. Using these devices, vortices may be perturbed at arbitrarily long wavelengths down to wavelengths less than a typical airliner wingspan and the oscillatory loads on the wings, and hence the vehicle, are small. Significant flexibility in the specific device has been demonstrated using local passive and active separation control as well as local circulation control via Gurney flaps. The method is now in a position to be tested in a wind tunnel with a longer test section on a scaled airliner configuration. Alternatively, the method can be tested directly in a towing tank, on a model aircraft, a light aircraft or a full-scale airliner. The authors believed that this method will have significant appeal from an industry perspective due to its retrofit potential with little to no impact on cruise (devices tucked away in the cove or retracted); low operating power requirements; small lift oscillations when deployed in a time-dependent manner; and significant flexibility with respect to the specific devices selected.
\end{abstract}

\footnotetext{
* Invited Paper for the $4^{\text {th }}$ AIAA Flow Control Conference, Seattle, Washington, June 23-26, 2008.

Senior Lecturer, Faculty of Mechanical Engineering. Senior Member; davidg@technion.ac.il.

${ }^{\dagger}$ Aerospace Engineer, Flow Physics \& Control Branch, Mail Stop 170.

${ }^{\ddagger}$ Graduate Student, Chair of Fluid Dynamics, Hermann-Föttinger-Institute, Berlin Institute of Technology, D-10623 Berlin, Germany; stefan.vey@pi.tu-berlin.de.

『 Professor, Chair of Fluid Dynamics, Hermann-Föttinger-Institute, Berlin Institute of Technology, D-10623 Berlin, Germany. Senior Member; oliver.paschereit@pi.tu-berlin.de.

$\S$ Research Scientist, Engine Acoustics, Institute of Propulsion Technology, Müller-Breslau-Str. 8, 10623 Berlin, Germany; robert.meyer@dlr.de.
} 
$4^{\text {th }}$ Flow Control Conference, Seattle, Washington, June 23-26, 2008

Nomenclature

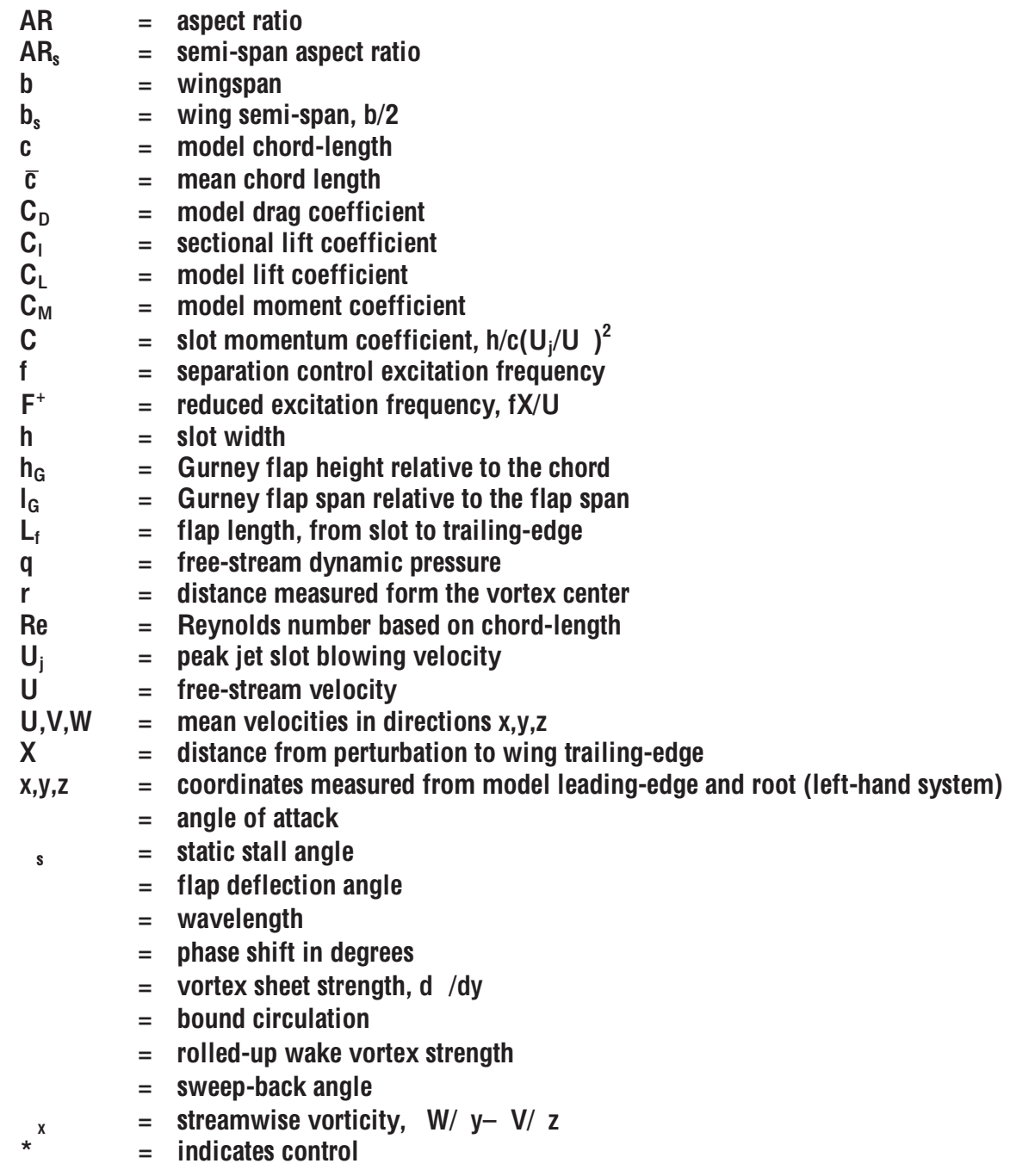

I. Introduction

T

he well-known hazard posed by powerful vortices trailing large commercial airliners (Spalart, 1998, Rossow, 1999) is particularly severe near airports where planes fly in close proximity and where the relatively low flight speeds result in increased vortex strength. Although the vortices are usually transported away by selfinduction or by atmospheric currents, this is not always the case and several accidents have been attributed to vortex encounters in recent decades. In order to safely avoid wake vortex encounters, inter-aircraft separation standards are enforced, where larger separation distances are imposed in the wakes of larger airliners. It has long been recognized that the wake vortex hazard is a major factor contributing to inefficient throughput and delays at busy modern airports. Moreover, with projected rapid increases in the demand for air transportation (Broderick et al, 2008) and ever-larger aircraft entering the fleet mix (Kingsley-Jones, 2006), it is expected that the increased hazard will be significant impediment to increased air traffic capacity.

Recent years have witnessed significant advances in wake detection methods, such as phase microphone arrays (e.g. Michel and Böhning, 2001), Lidar (e.g. Schmitt et al., 2007) and opto-acoustic sensor arrays (e.g. Fine and Kring, 2005), as well as prediction and simulation (Frech and Holzäpfel, 2008). Effective detection and prediction are vital to accurately quantify a 'hazard boundary' that is used to judge if a given encounter is acceptable (Broderick et al, 2008). Significant potential, however, appears to be associated with vortex alleviation techniques that aim to directly 
reduce the wake severity by modifying its vortex characteristics. This could potentially reduce aircraft-following distances behind the "vortex-alleviated" aircraft (see Savas et al, 2005, Crouch, 2005 and Broderick et al, 2008). The viability of a vortex alleviation method is quantified by a reduction in the severity and probability a vortex encounter and the 'hazard boundary' can be invoked in the manner mentioned above. Vortex alleviation techniques employed, however, must not degrade performance or compromise safety and ride quality.

Effective Vortex alleviation methods fall into two broad categories: time-invariant and time dependent methods. The former relies on modifying the span loading to establish two or more pairs of opposite-signed counter-rotating vortices and allow naturally arising instabilities to bring about their linking and mutual destruction (Rennich and Lele, 1999, Rossow, 1975, Cliffone, 1975, Ortega et al, 2003, Fabre et al., 2002, Durston et al., 2005; Savas, 2005). In many instances, the required configuration modifications adversely affect aircraft performance and this limits their potential implementation (Broderick et al, 2008). The latter method actively forces the breakup of vortices, for example, by pitching the vehicle (Chevalier, 1973) or differentially and time-dependently deflecting inboard and outboard control surfaces ("sloshing" of the lift distribution; Crow,1971, Crow and Bate, 1976; Haverkamp et al., 2005). This method was tested in a towing tank (Bilanin and Widnall, 1973), where measured amplification rates agreed qualitatively with theoretical predictions. Recently, a similar approach was pursued with a view to exploiting the multiple vortex growth mechanisms created by an airplane on approach with flaps-down (Crouch el al, 2001). Another approach exploits transient growth or bypass mechanisms of the vortex pair (Pradeep and Hussain, 2006; Brion et al., 2007). Despite their inherent appeal, active methods must address issues such as "ride quality, dynamicload effects on the structure, and the ability to maintain control authority during operation" (Crouch, 2001).

In the final analysis, it is not sufficient for alleviation methods to be effective. In addition, they must not degrade performance, not compromise safety and ride quality and it is advantageous if they are aircraft independent, weather independent, predictable and measurable. Furthermore, they should be of a form that is acceptable to aircraft manufactures, pilots, air traffic controllers and passengers (Broderick et al, 2008).

\section{Objective \& Scope}

The objective of this paper is to describe a general method for managing wake vortices by means of local control of the bound wing circulation in the vicinity of vortex rollup origin. In contrast to other methods, we argue for vortex alleviation schemes that are decoupled from conventional existing control surfaces. The approach that we have adopted is experimental. As will be shown, we have used a number of techniques and all have shown promise in the near wake. The main reason for this is that each approach, passive or active, is rooted in the hypothesis of Betz (1933), as extended ingeniously by Donaldson and his collaborators (Donaldson et al, 1974).

All work presented is based on two experimental investigations: the first was conducted at NASA LaRC (supported by the National Research Council; Greenblatt, 2005, 2006; Greenblatt et al, 2005); and the second was conducted at the Berlin University of Technology in collaboration with the German Aerospace Center (DLR) (Vey et al, 2008). The approach adopted here was to build the concept from the ground up, namely: (a) hypothesis, (b) simple experiment as demonstration of concept, and (c) more complex experiment approaching an airliner configuration.

A note on terminology: the terms "active control" and "passive control" have the potential for terminology confusion. This is because we are controlling both the local circulation or separation on the flap or wing as well as managing the wake. The term "circulation control" here refers to any alteration of the local wing bound vortex that does not involve direct control of separation. We also need to distinguish between control of the flow on the flap or wing and management of the wake vortices; these nomenclature are summarized in table 1. For example, a passive circulation control (PCC) device such as a Gurney flap, may be deployed in a time dependent manner, leading to active wake perturbation (AWP). A similar result can be achieved with a traditionally passive separation control (PSC) device such as a vortex generator. Alternatively, active separation control (ASC) such as zero mass-flux blowing, can be operated in a time-independent manner (or at time-scale not related to the wake instabilities) to exploit a passive wake management (PWM) method. The table shows six possible independent combinations, but there is no reason why the different methods cannot be combined.

Table 1. Summary of the nomenclature adopted here.

\begin{tabular}{|l|l|l|}
\hline & Time Invariant deployment & Time dependent deployment \\
\hline Passive circulation control (PCC) & $\begin{array}{l}\text { Passive Wake Management } \\
\text { (PW Wassive separation control (PSC) }\end{array}$ & $\begin{array}{l}\text { Active Wake Perturbation } \\
\text { (AWP) }\end{array}$ \\
\cline { 1 - 2 } Active separation control (ASC) & & \\
\hline
\end{tabular}




\section{Flap-Vortex Control Basics}

All modern airlines have the following in common: they all deploy flaps for takeoff and landing. Thus in the flight regimes where the hazard is most severe, namely low speed flight in the vicinity of airports, the flap-edge vortex dominates the ensuing wake structure. This is observed in wind tunnel investigations (de Bruin et al, 1996; Bellastrada et al, 2002) and flight measurements (Donalson et al, 1974), but is also clearly evident when observing the contrails in cold or humid weather (see photographs in fig. 1). The pressure drop in the vortices is proportional to

${ }^{2}$, and the accompanying drop in temperature produces the contrails visible in the photographs.
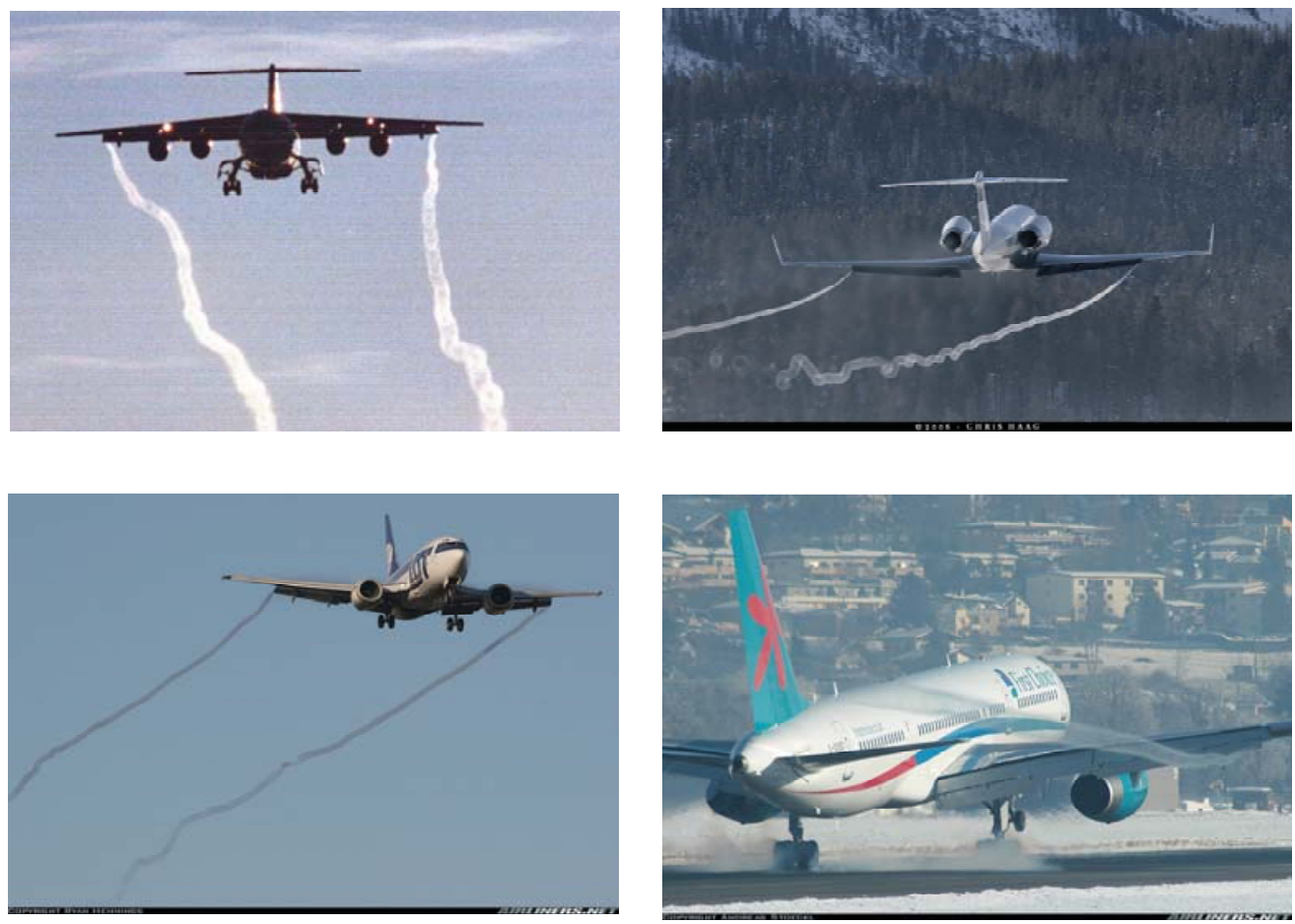

Fig. 1. Photographs showing condensation in flap-edge vortices. From the top left (clockwise) Jan-Olov Newborg; Chris Haag; Ryan Hemmings; Andreas Stoeckl. All photographs reproduced with express permission. Source of lower two figures: airliners.net.

Controlling separation or circulation locally, i.e. over some fraction of the flap-span, in the vicinity of the flap edge, directly affects lift or bound circulation and therefore modifies the vortex sheet strength (or shed vorticity) $=d / d y$. Since the vortex sheet at the flap edge rolls up into the dominating vortex, local separation or circulation control are strong candidates for directly controlling, or managing, the vortices. Furthermore, decoupling vortex management from the control surfaces and only applying it selectively, ensures relatively small wing-load excursions. The aforementioned assertions were initially made by the first author (Greenblatt, 2005, 2007) based on the method of Betz (1933) as extended by Donaldson et al (1974). The principle computation advantage of Betz's method is that it does not explicitly treat the rollup mechanism, but rather employs three conservation relations between the span-loading $(y)$ and the rolling-up vortex $(r)$. Betz employed the conservation of vorticity and also postulated that the first and second moments of vorticity are conserved: these are referred to as the inviscid rollup relations. Despite the relative simplicity of the method, it predicts flap vortex details that are in surprisingly good agreement with full-scale airliner flight tests (Donaldson et al, 1974).

The basics of the technique, from an active flow control perspective, are described in more detail with respect to fig. 2. The top part of the figure (a) is a schematic of an aircraft with a flap deflected. The second level (b) shows the lift (or circulation) variation along the span; the third part (c) represents the absolute value of the vortex sheet |d /dy|; and the lower part of the figure (d) shows the theoretically predicted rolled-up vortices in the Trefftz plane. 
Schematic data is presented for baseline and controlled cases (asterisks indicate control), where the control input is supplied in the vicinity of the flap edge. Two key aspect of Donaldson's extension are that the vortex rolls up from the spanwise locations corresponding to local $|\mathrm{d} / \mathrm{dy}|_{\max }$ and the segment of the sheet between the adjacent two $|\mathrm{d} / \mathrm{dy}|_{\min }$ are rolled up into the flap vortex. This was verified in a series of full-scale flight tests (Donaldson et al, 1974). For clarity, the figure shows an exaggerated effect of control applied locally near the flap edge. It thus becomes evident that the flap-edge vortex, and particularly its centroid, is relatively easy to perturb without producing large overall load changes. If the method is deployed in a time dependent manner, then time dependent perturbations can be introduced, in a manner that is effective decoupled from the control surfaces.

(a)

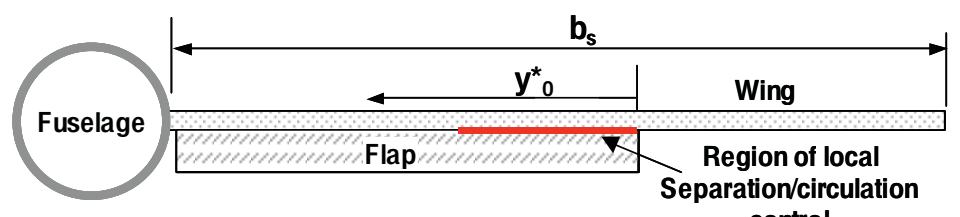

(b)

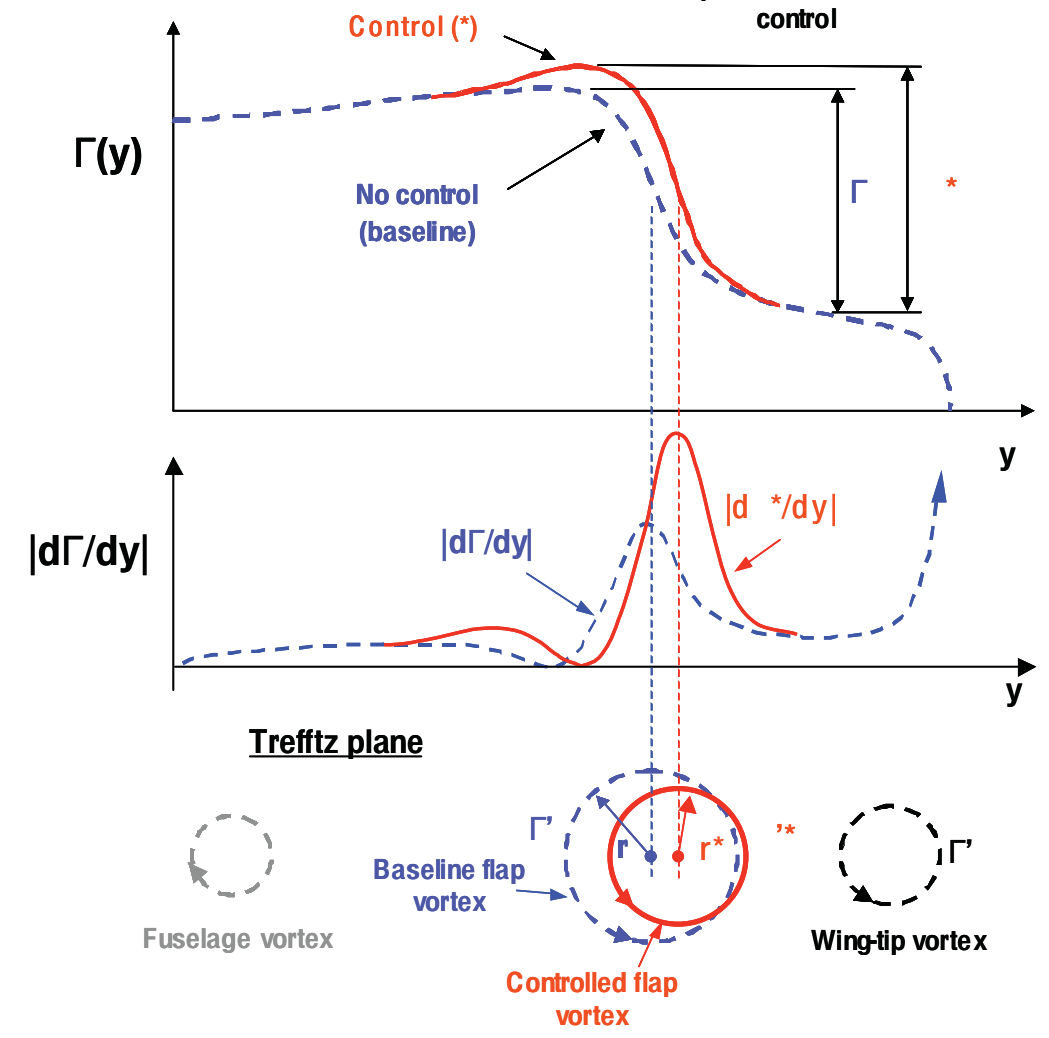

Fig. 2. Schematic illustrating the essential elements of the Donladson-Betz Method. (a) wing and flap configuration; (b) effect of control on the spanwise wing loading; (c) effect of control on the vortex sheet; (d) rolling-up vortices in the Trefftz plane. Asterisks (*) indicate the controlled case.

\section{Proof of Concept}

A. Static Experiments - Inboard Flap Deflection

Initial experiments were performed as a pilot study on a simply flapped semi-span airfoil model to investigate the concept and viability of near-wake vortex management by means of boundary layer separation control. The model used was a NACA 0015 profile $(\mathrm{AR}=4)$ and was equipped with zero mass-flux blowing slots, as well as multiple surface pressure ports (see fig. 3 and further details in Greenblatt, 2005, 2007). Passive control was 
achieved using a simple fairing placed over a control slot and active control was achieved via zero mass-flux blowing from the slots. The varying lift distribution $(y)$, and hence the vortex sheet strength $d / d y$, was estimated by integrating the surface pressures. The vortex sheet strength was then used, together with the rollup relations of Donaldson and Betz, to predict vortex characteristics. Furthermore, vortices trailing the flaps were mapped using a seven-hole probe in the near wake $(x / c=2)$. Boundary layer separation control was found to have a marked effect on vortex location, strength, tangential velocity, axial velocity and size over a wide range of angles of attack and control conditions. In general, the vortex trends were well predicted by the inviscid rollup relations. Manipulation of the separated flow near the flap edges exerted significant control over either outboard or inboard edge vortices while producing small lift and moment excursions.

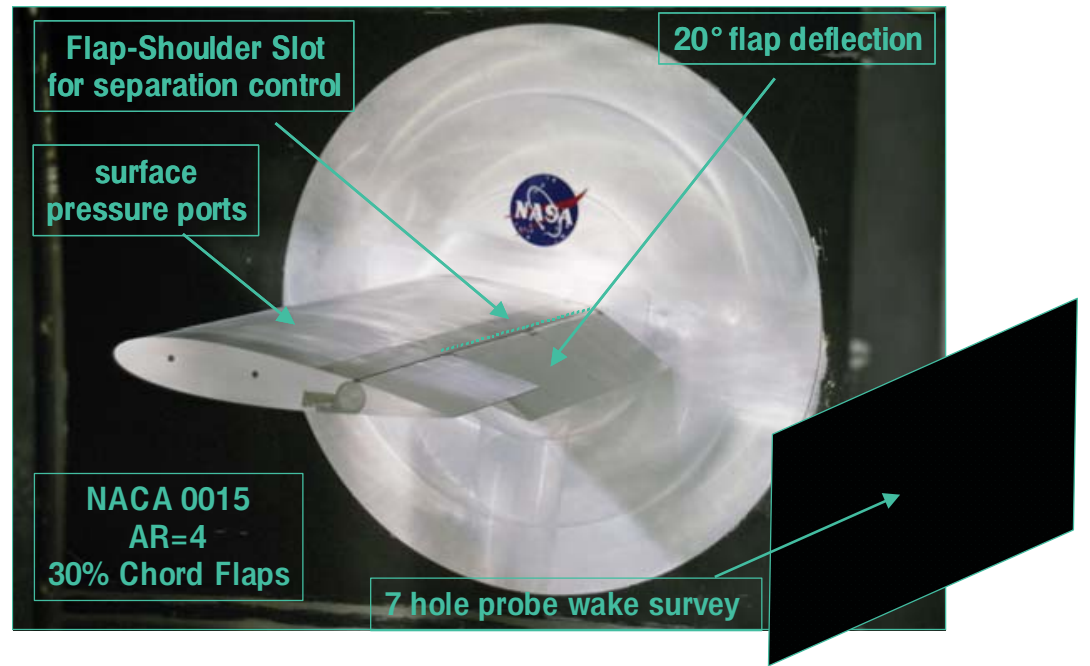

Fig. 3. Photograph of the semi-span wing model used at NASA Langley Research Center, showing the inboard flaps deflected at 20 degrees and measurements.

As an example, consider the difference in span loading for inboard and outboard control for the passive case (fig. 4a) and an active case (fig. 4b). The active case was selected such that both inboard and outboard control produce similar $C_{L}$ and $C_{M}$ (see Greenblatt, 2007). Corresponding wake vorticity, based on seven-hole probe measurements at $x / c=2$ for passive and active control, are shown in figs. $5 a-5 d$. Changes to the vortex characteristics between inboard and outboard control, both passive and active, are compared with those calculated from the rollup relations in table 2. In general, the predictions of centroid movement and peak velocity ratio are good, while vortex strength and size ratio only show the correct trends. Both rollup relations and wake measurements show the surprising result that passive control has a larger effect on the vortex centroid. This is because the fairing was applied on the outboard slot to seal it and produce only inboard control and vice versa. This results in partial separation control over the part of the slot with the fairing and hence active control appeared to produce a smaller effect on the centroid than passive control. Nevertheless, this serves to emphasize the fact that controlling the vortex sheet-strength in the vicinity of the flap edge can have a large effect on the centroid without significant changes to the overall aerodynamic loads. The comparison in table 2 also serves to illustrate the limitations of the rollup method. For example, simple passive control increases the vortex strength by $23 \%$ where this is not evident from the $5 \%$ increase predicted from the spanloading. The main reason for the poorer predictions is that the method neglects viscous effects, which become more important when dealing with the rollup of separated shear layers. Additional data acquired on a deflected outboard flap indicated vortex changes of $\bar{y} / b_{s} \quad 2.5 \%$ trailing the outboard edge of the flap and $\bar{y} / b_{s} \quad 2.7$ trailing the inboard edge. 

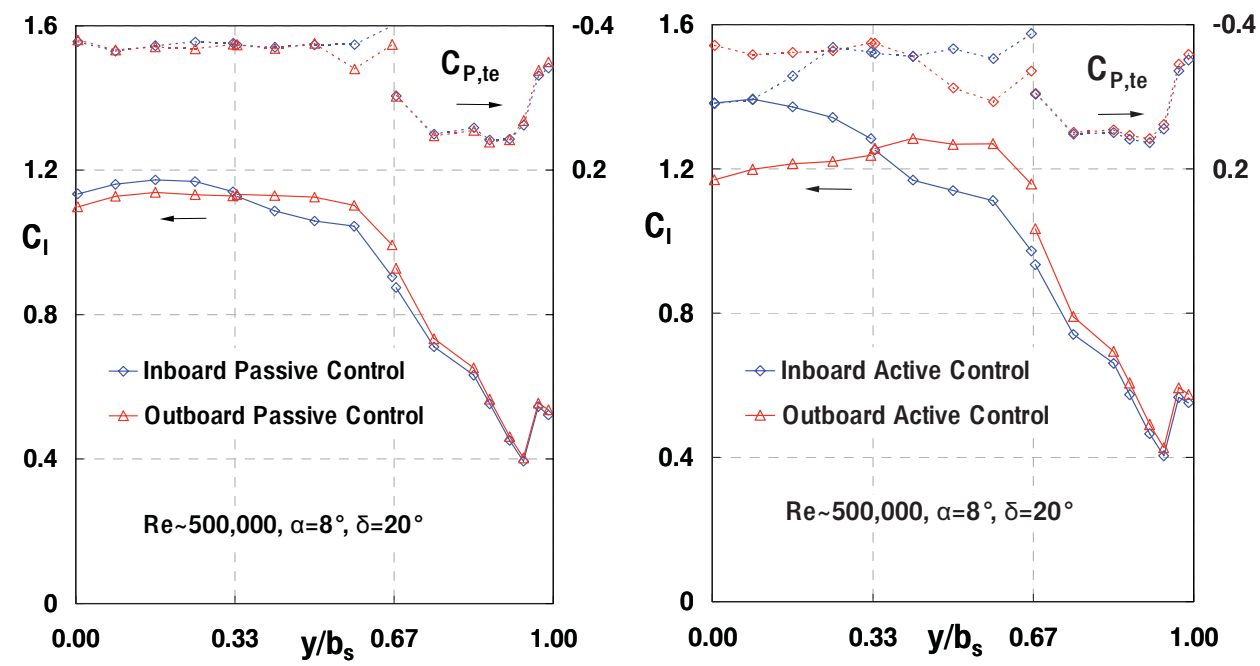

Fig. 4. Span-loading for (a) passive and (b) active inboard and outboard control.
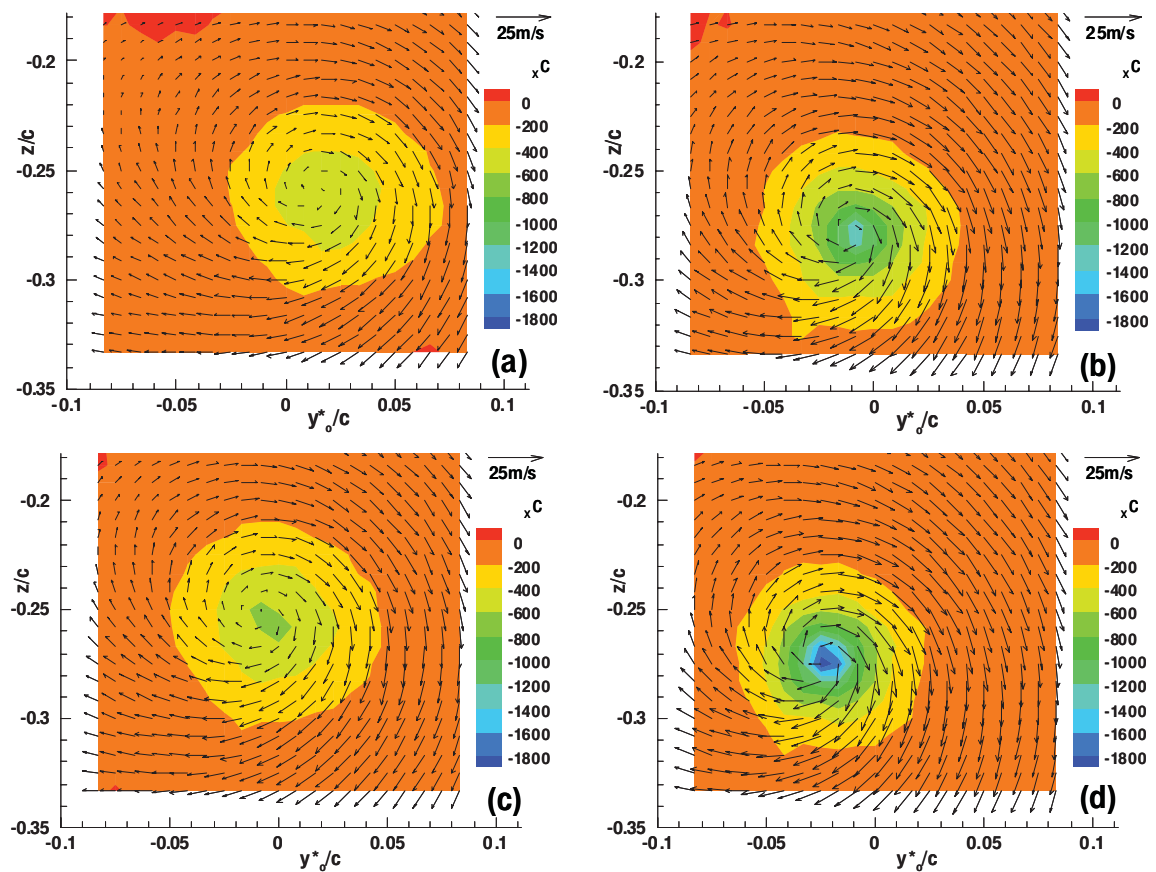

Fig. 5. Seven-hole probe measurements of axial vorticity and in-plane velocity for the scenarios: (a) passiveinboard control; (b) passive outboard control; (c) active-inboard control; (d) active outboard control (x/c=2).

In summary, the pilot study indicated that local separation or circulation control has the potential for application to time-independent or time-dependent wake alleviation schemes, where the latter can be deployed to minimize adverse effects on ride-quality and dynamic structural loading. 
Table 2. Comparison of vortex changes based on inviscid rollup relation predictions and near-wake measurements.

\begin{tabular}{|c|c|c|c|c|}
\cline { 2 - 5 } \multicolumn{1}{c|}{} & \multicolumn{2}{c|}{ Partial Flap-Passive Control } & \multicolumn{2}{c|}{ Partial Flap-Active Control } \\
\cline { 2 - 5 } \multicolumn{1}{c|}{} & 7-hole Probe & Donaldson-Betz & 7-hole Probe & Donaldson-Betz \\
\hline$\overline{\mathrm{y}} / \mathrm{b}_{\mathrm{s}}(\%)$ & 1.3 & 1.5 & 0.82 & 0.78 \\
\hline$/$ & 1.23 & 1.05 & 1.17 & 1.27 \\
\hline $\mathrm{V}_{,{ }_{\text {max }}} / \mathrm{V}_{\text {,max }}$ & 1.30 & 1.29 & 1.38 & 1.45 \\
\hline $\mathrm{r}_{1} / \mathrm{r}_{1}$ & 0.71 & & 0.62 & \\
\hline $\mathrm{r}_{2} / \mathrm{r}_{2}$ & & 0.82 & & 0.88 \\
\hline
\end{tabular}

B. Dynamic Experiments - Tip-Flap Deflection

In a follow-up study, the effect control over a deflected flap at the wingtip was investigated. One of the primary motivations was that optical access for particle image velocimetry (PIV) was possible on the tip flap, but not possible on the inboard flaps due to limitations of the tunnel optical access. These data revealed that control over the centroid was significantly less than that achieved on the inboard flaps, but the effect on the axial velocity within the vortex was dramatic, with the change in flow direction being on the order of magnitude of the free-stream velocity (see Greenblatt et al, 2005). Much of this study was directed at unsteady effects and the relationship between separation, or circulation, control time-scales and wake management time-scales; a brief summary and experimental data set are presented below.

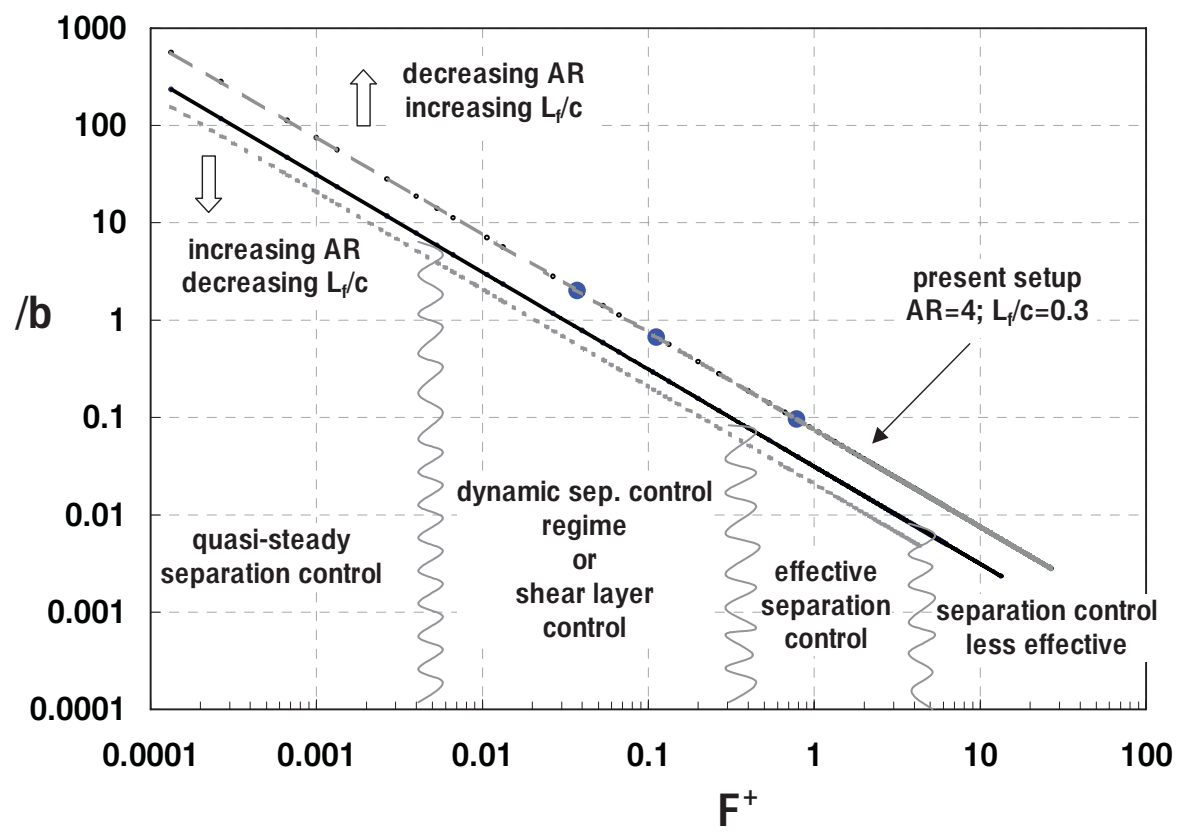

Fig. 6. Relationship between trailing vortex wavelength and separation control frequencies. Solid line is for $\mathbf{A R}=8, L_{f} / C=0.25$; Top line corresponds to the NASA Langley semi-span wing employed in this study.

To express wake instability wavelengths in terms of as separation control frequencies, we write the wavelength as a fraction of wingspan /b $U / \mathrm{fb}$ and define the general ratio $\quad X_{\mathrm{te}} / \overline{\mathrm{c}}$ (which is $L_{\mathrm{f}} / \mathrm{c}$ for the present setup). Using the definition of $F$ we can then write /b / $\quad A R$ and plot /b versus $F$ for various values of and AR (see fig. 6). The solid line represents a "typical" airliner configuration ( 0.25 and AR 8 ) and the top 
hatched line represents the present configuration ( $\quad 0.3$ and AR 4 ; see section IV.A). Note that the line moves up with increasing and decreasing $A R$, and vice versa. We note from fig. 6 that the high end of the effective separation control frequencies (approximately $\mathrm{F}^{+} 3$ ), correspond to wavelengths $/ \mathrm{b}<<1$. This is somewhat less than typical "braid" instabilities identified by Williamson et al. (1998). The opposite end of the effective separation control spectrum, $\mathrm{F}^{+} 0.3$, corresponds approximately to the upper end of the braid instability, $/ \mathrm{b}=0(0.1)$. Thus, effective separation control frequencies correspond to typical braid instability wavelengths. For $\mathrm{F}^{+}<0.3$, separation control begins to loose its effectiveness and the boundary layer begins to stall dynamically. Nevertheless, if higher frequency separation control perturbations $\left(F^{+} 1\right)$ are modulated at a lower frequency $f_{\text {mod }}$, then the shear layer can be forced to dynamically attach and separate at $F_{\text {mod }} f_{\text {mod }} L_{f} / U \sim 0.1$. This corresponds to the short-wave instability identified by Williamson (1998) with /b O(1). Modulation can be performed at even lower frequencies, corresponding to longer wavelength instabilities such as those identified by Crouch et al. (2001) or Crow (1970) with $/ b>1$. Clearly, relatively high frequency separation control frequencies $\left(0.3 \mathrm{~F}^{+} 3\right)$ can be modulated in a quasi-steady manner to achieve arbitrary long-wave vortex perturbations, corresponding to $/ b>>1$. At the other end of the frequency spectrum, when perturbations are introduced typically at $\mathrm{F}^{+}>3$, control perturbations are ineffective for boundary layer control and dissipate downstream. This corresponds to $/ c<<1$ and is also not of obvious importance from a vortex perturbation standpoint.

Vortex perturbation using separation control is clearly possible for large range wavelengths. From a wake vortex alleviation viewpoint, we are most interested in the case where wake perturbation wavelengths are $/ b \sim 0(1)$. As mentioned above, separation control looses effectiveness below $\mathrm{F}^{+} \mathbf{0 . 3}$, and therefore to perturb vortices at wavelengths corresponding to the wingspan and larger, we must resort to control perturbation modulation in order to force dynamic attachment and separation of the shear layer. It is thus convenient to define a modulation frequency $f_{\text {mod }}<<f_{e}$. Two different modulation techniques were employed: square-wave modulation (sometimes called "burst modulation"); and sinusoidal modulation; the "carrier wave" frequency $\mathrm{f}_{\mathrm{e}}$ corresponds to $\mathrm{F}^{+}=0.78$ at $\mathrm{C}=0.14 \%$. Modulation was selected at $F_{\bmod } \quad 0.04$ corresponding to $/ \mathrm{b}=2$ and stereoscopic PIV measurements were made at the downstream location $\mathrm{x} / \mathrm{c}=7.2$.

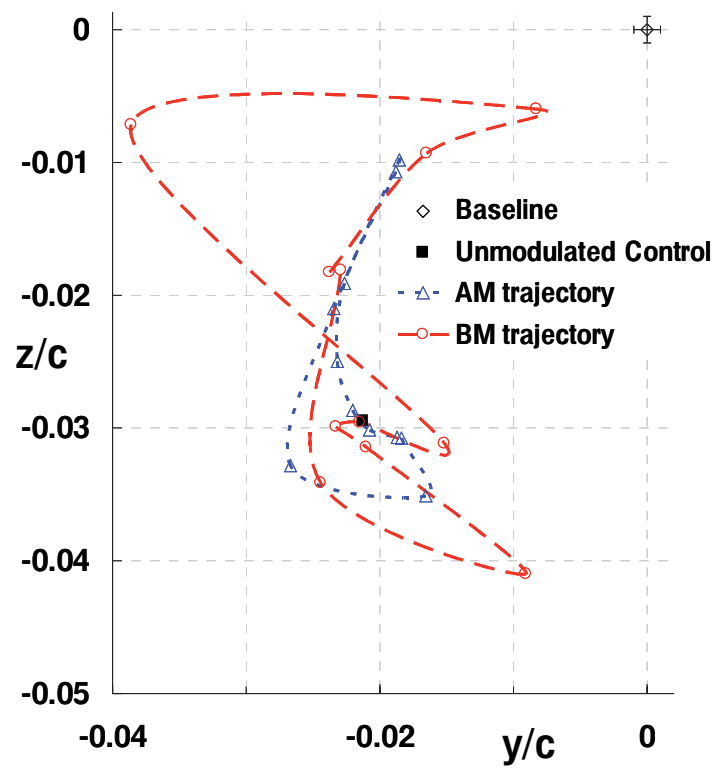

Fig. 7. Fig. 18. Vortex centroid trajectories for sinusoidal and burst modulation of the forcing signal. Data for dynamic separation control corresponding to $/ b=2$. 
Fig. 7 shows the effect of both static and dynamic perturbations on the vortex centroids. The effect of separation control (static perturbation) is to move the vortex downwards and outboard, i.e. ( $y / c, z / c)(2.2,3.0) \%$. Modulation at $F_{\text {mod }} \mathbf{0 . 0 4}$ has a markedly different effect depending upon the modulation waveform; in both instances shown here the flow always remains in a state of partial separation. In the case of sinusoidal modulation the vortex centroid excursions are reduced to $(y / c, z / c) \quad(1.0,2.5) \%$, primarily because the flow is never fully separated or attached to the flap. However, when burst modulation is employed the excursions increase to ( $y / c, z / c)(3.0,3.5) \%$. There are two main reasons for this. Firstly, the flow approaches fully separated and attached states to a greater degree than that for sinusoidal perturbation due to the abrupt nature of both the perturbation initiation and termination. Unsteady pressure measurements on the flap revealed that there is an overshoot of the static flap pressures as a result of the modulation (Greenblatt, 2005). This accounts for the larger movement of the vortex centroid that results from burst modulation. This was observed at wavelengths as small as $/ \mathrm{b}=0.4$, despite the fact that the flow did not fully attach or fully separate. The unsteady loads on the main element, however, reduced in magnitude. Thus it was demonstrated that dynamic perturbation of the wake vortices can increase control authority while simultaneously reducing the already small unsteady loads.

\section{Limitations of the Pilot Study}

Although the above investigations did show the basic proof of concept, from a wake vortex alleviation viewpoint it suffered from a number of deficiencies: (i) the investigation was conducted on a semi-span model with simple flaps and not high-lift devices encountered on modern airlines; (ii) the model did not incorporate sweep that is prevalent on all modern airliners; (iii) wing loads were not explicitly measured, but rather inferred from surface pressure measurements; (iv) only near-field $(\mathrm{x} / \mathrm{c}=2)$ vortex measurements were made. In addition, local separation control was employed and this was based on the premise that (a) separation occurs on the flaps or (b) separation can be enforced locally on the flaps. It was asserted that this may somewhat limit the generality of the method. The four points mentioned above, in addition to the limitation imposed by separation control, were addressed in a follow-up investigation conducted at the Berlin University of Technology in conjunction with the German Aerospace Center (DLR).

\section{Towards an Airliner Configuration}

\section{A. The Experimental Configuration}

The experimental investigation performed at the Berlin University of Technology was undertaken with the express purpose of redressing the deficiencies mentioned in the previous section. This investigation was conducted on a swept constant-chord half-model (fig. 8) incorporating a modern transonic airfoil of a commercial European airliner ( $=30, b_{s}=1.12 \mathrm{~m}, c=0.45 \mathrm{~m} ; A R=5$ ) and a modern three-element high-lift system. The inboard flap and fulllength leading-edge slat were set for a typical landing configuration, with a $=32$ flap angle and a 26.5 slat angle (fig. 8b; more details can be found in Vey et al, 2008).

In order to remove any association with separation control, Gurney flaps were used for locally altering the span loading, i.e. vortex-sheet strength, in the vicinity of the flap edge. These were made from $0.5 \mathrm{~mm}$ sheet metal and were fitted to the flap trailing edge. Gurney flap height relative to the chord was designated $h_{G}$ and Gurney flap length relative to the flap span was designated $I_{G}$. The investigation was divided into two phases: phase I involved the static testing of different finite flap-span Gurney flaps (PCC/PWM) in order to isolate the most promising configurations (see fig. 9a); phase II employed dynamic control of the system, i.e. oscillatory deployment of Gurney flaps (PCC/AWP) using the configurations isolated in phase I. To achieve this, the Gurney flap was hinged at the flap trailing-edge and was driven by pushrod actuation. The pushrod was driven by an electric motor and a cam assembly that was installed in the fuselage of the model. A schematic of the Gurney flap is shown in fig. $9 \mathrm{~b}$.

For the static case, aerodynamic loads were measured by means of a six-component force-balance. Furthermore, the inboard flap was equipped with five rows of pressure ports at the flap edge. The main element incorporated one row of pressure ports corresponding to the location of the flap edge. The wind tunnel test section was $10 \mathrm{~m}$ long facilitating wake measurements within the range $x / b 4.5$ ( $x / c$ 22). Vortex centroids and strength were estimated from planar two-dimensional particle image velocimetry (PIV) measurements at the two downstream locations $\mathrm{x} / \mathrm{c}=4$ and $x / c=9$ corresponding to $x / b=0.80$ and $x / b=1.81$ respectively. (The unexpected phenomenon of flap-edge vortex breakdown at x/c 15 precluded meaningful measurements further downstream; see discussion below). 


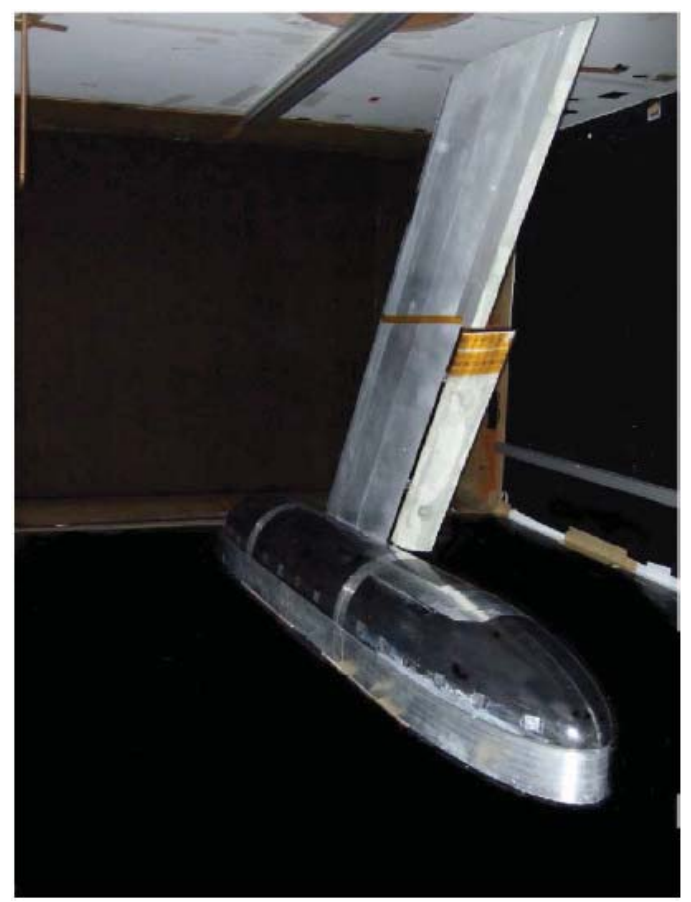

Fig. 8. Photograph of the SCCH-model used in the experimental study at the Berlin University of Technology, installed in the ISTA $2 \mathrm{~m} \times 1.41 \mathrm{~m}$ closed loop return wind tunnel. Inboard flap deflected to 32 (landing configuration).
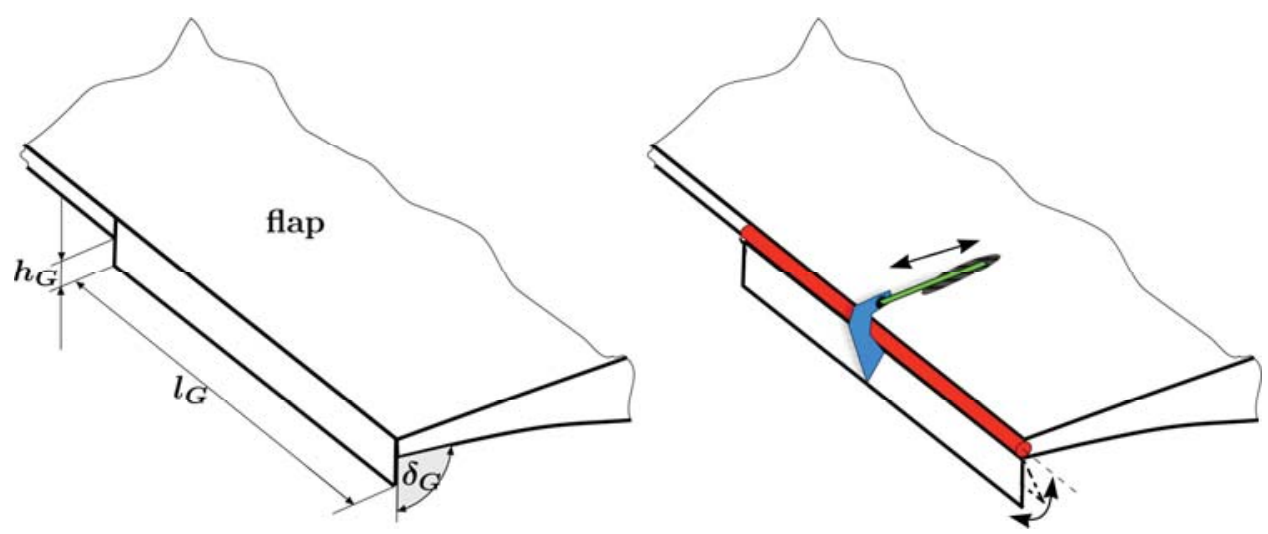

Fig. 9. a) Static Gurney flap dimensions and b) Active Gurney flap hinged at trailing edge of flap. Hinge: red, pushrod: green, horn: blue.

B. Static Vortex Measurements

An example of PIV measurements, conducted at $\mathrm{Re}=500,000$ and $=5$ are shown in fig $10 \mathrm{a}$ to $10 \mathrm{~d}$. The vorticity field $x$ was calculated from the average velocity field, based on 300 image pairs, where several Gurney flap heights and lengths were tested to determine the dependence of centroid and vortex strength on the specific configuration. A selection of various cases is shown in the figure where the vorticity fields are depicted for four different configurations. 
$4^{\text {th }}$ Flow Control Conference, Seattle, Washington, June 23-26, 2008
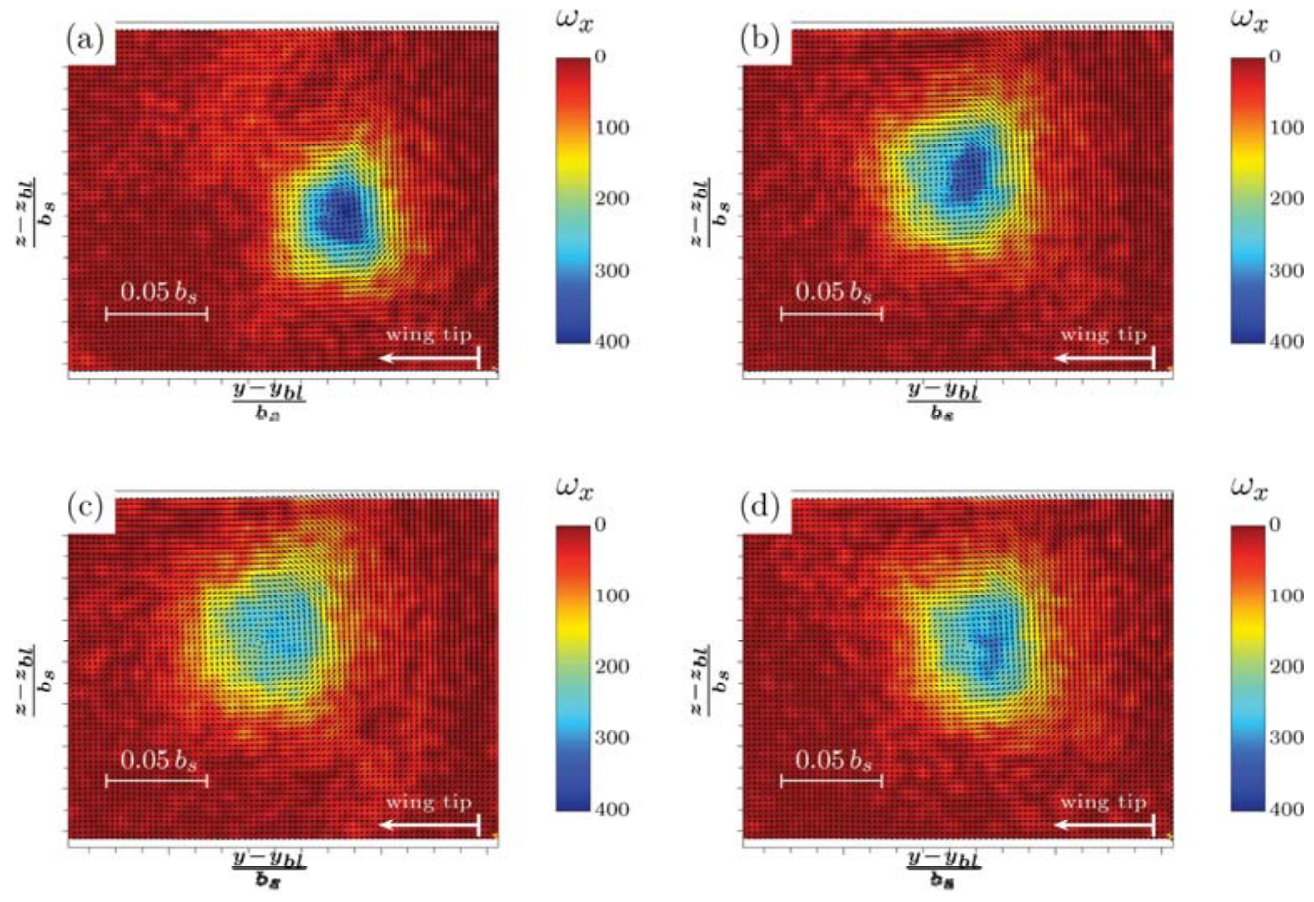

(c)

(d)

Fig. 10. Vorticity and velocity fields at $x / c=4$ for: a) baseline b) $h_{G}=2 \%, I_{G}=30 \%$ c) $h_{G}=4 \%, I_{G}=30 \%$ d) $\mathrm{h}_{G}=2 \%, \mathrm{I}_{G}=40 \%, 2 \%$ off the trailing-edge.

Centroids calculated from the vorticity fields are shown in fig. 11. There is an optimum in Gurney flap length in terms of spanwise centroid shift for the $2 \%$ and the $4 \%$ Gurney flap at $I_{G}=30 \%$ for the $x / c=4$ position. This observation is fully consistent with the Donaldson-Betz theory, as changes to local bound circulation near the flap edge have the largest effect on the vortex centroid. As the bound circulation is varied further inboard by the extended Gurney flaps, as expected, this has a diminishing effect on the flap-edge vortex.

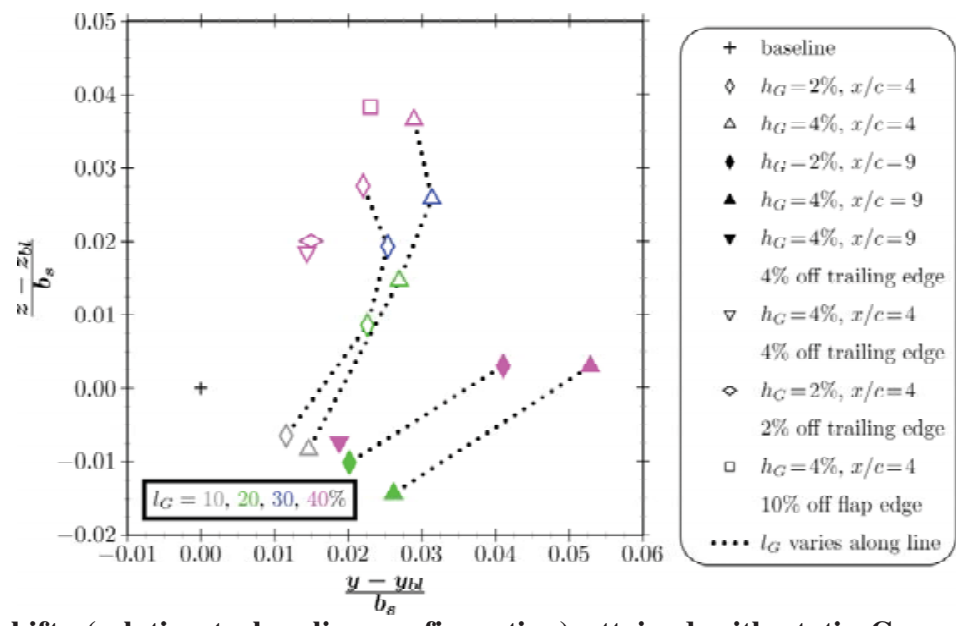

Fig. 11. Centroid shifts (relative to baseline configuration) attained with static Gurney flap. Dotted lines denote varying Gurney flap length $I_{G}$, while height $h_{G}$ is kept constant; $R e=500,000,=5$

Configurations were also tested where the Gurney flaps were located at $2 \%$ and $4 \%$ of chord from the trailing edge towards the leading edge. Similar configurations have been tested in flight and it is assumed that this is done 
for reasons related to structural integrity (e.g. Hansen, 2003). Vortex centroid authority in these cases was found to be significantly reduced when compared to a Gurney flap that is placed flush with the trailing edge. This result is supported by the findings of $\mathrm{Li}$ et al (2003) who varied Gurney flap deflection angle and distance from the trailing edge. They found that Gurney flap efficiency is highly dependent on distance of placement from the trailing edge. Furthermore, Gurney flap placement inboard of the flap edge towards the root was also tested. The motivation was related to developing a vortex perturbation scheme where the Gurney flap slides periodically along the trailing edge. For these cases no pressure measurements or load measurements were made.

PIV measurements revealed that the lateral (spanwise) and longitudinal vortex centroids behaved differently with downstream distance. In the former case, centroid displacement increased with downstream distance for both $\mathrm{h}_{\mathrm{G}}=2 \%$ and $\mathrm{h}_{\mathrm{G}}=4 \%$, but longitudinal displacement tended to zero in the later case. Based on theoretical considerations, the vortex further downstream that has rolled-up more of the vortex sheet and is thus more representative of the changes to the loading on the wing and, in particular, near the flap-edge. Flap edge pressure measurements confirmed the relatively strong local effect of the Gurney flaps in this region (Vey et al, 2008).

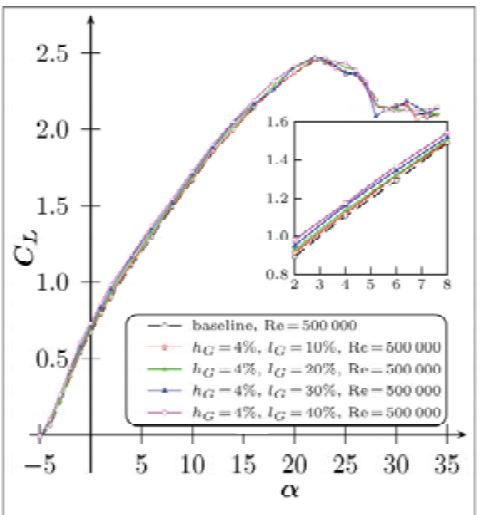

(a)

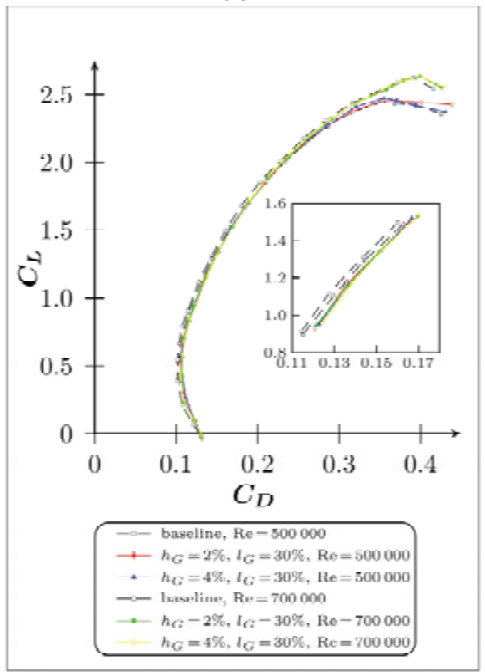

(c)

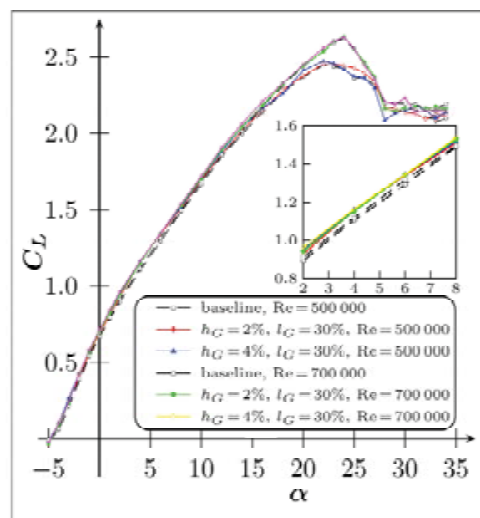

(b)

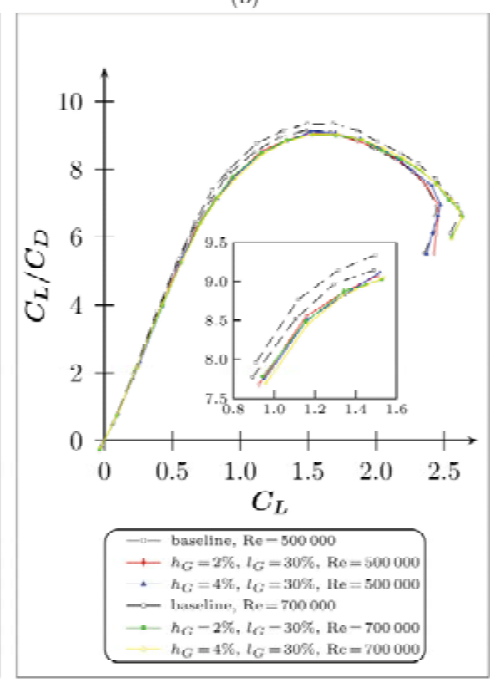

(d)

Fig. 12. Influence of Gurney flaps on aerodynamic loads: a) $C_{L}$ vs for varying Gurney flap length; b) $C_{L}$ vs

for varying Gurney flap height; c) $C_{L}$ vs $C_{D}$ (same configurations as in b); d) Aerodynamic efficiency $\left(C_{L} / C_{D}\right)$ vs $C_{L}$. Same Gurney flap configurations in b), c) and d); $R e=500000$ and 700000.

To quantify the changes in lift $\left(C_{L}\right)$ and drag $\left(C_{D}\right)$ coefficient for different Gurney flap configurations, load measurements were carried out. Aerodynamic coefficients are based on the geometry of the un-flapped wing (see Vey et al, 2008 for more details) and some representative data are shown in fig. 12a-12d. As expected, at a 
particular angle of attack, the lift coefficient is shifted towards slightly higher values with larger Gurney flap length; and the same effect can be seen for larger Gurney flap height (fig. 12b). Nevertheless, these changes are very small: changes in $C_{L}$ and $C_{D}$ are summarized in table 3 for an angle of attack $=5$ at $R e=500,000$. Moreover the dependence of $C_{L}$ on both Gurney flap height and length is very weak. For example, with $I_{G}=30 \%$ at $=5$ an increase in flap height by from $2 \%$ to $4 \%$ produces a change in $C_{L}$ of less than 0.01 .

Table 3: Changes in $C_{L}$ and $C_{D}$ at $=5$ for different Gurney flap configurations, based on direct load measurements at $R e=500,000$.

\begin{tabular}{|c|c|c|c|c|}
\cline { 2 - 5 } \multicolumn{1}{c|}{} & $\mathrm{h}_{G}=2 \%$ & $\mathrm{~h}_{G}=2 \%$ & $\mathrm{~h}_{G}=4 \%$ & $\mathrm{~h}_{G}=4 \%$ \\
\cline { 2 - 5 } \multicolumn{1}{c|}{} & $\mathrm{I}_{G}=30 \%$ & $\mathrm{I}_{G}=40 \%$ & $\mathrm{I}_{G}=30 \%$ & $\mathrm{I}_{G}=40 \%$ \\
\hline $\mathrm{C}_{\mathrm{L}}$ & 0.0495 & $\mathbf{0 . 0 5 3 3}$ & $\mathbf{0 . 0 5 5 7}$ & $\mathbf{0 . 0 7 2 2}$ \\
\hline $\mathrm{C}_{D}$ & $\mathbf{0 . 0 0 6 3}$ & $\mathbf{0 . 0 0 8 5}$ & $\mathbf{0 . 0 0 7 5}$ & $\mathbf{0 . 0 1 6 3}$ \\
\hline
\end{tabular}

It can be seen from figs. $10 \mathrm{c}$ and $10 \mathrm{~d}$ that drag increases slightly and consequently the aerodynamic efficiency $\left(C_{L} / C_{D}\right)$ decreases when Gurney flaps are installed, but these changes are relatively small with the wing in landing configuration (see inset). However, to address the problem of increasing drag, three-dimensionality can be added to the Gurney flaps by means of slits or holes (see Meyer et al, 2006). The introduction of the three-dimensionality suppresses vortex-shedding, thereby reducing drag. Nevertheless, changes to $C_{L}$ are not materially affected by the three-dimensionality and this produces an increase on efficiency.

\section{Dynamic Vortex Measurements}

Two Gurney flap configurations were considered in the dynamic measurements: $h_{G}=2 \%$ and $h_{G}=4 \%$ both with a length of $I_{G}=30 \%$. The $I_{G}=30 \%$ configurations were chosen for active Gurney flap tests based on the trends shown in fig. 11. Forcing frequencies tested, and corresponding perturbation wavelengths are listed in table 4 . The data in figs. 13a to $16 \mathrm{~b}$ are not corrected for phase-shift resulting from the finite time delay between the flap-edge trailingedge and the measurement location; the oscillating Gurney flap phase shift angles are given in table 4. The wavelength of the most unstable mode of the Crow instability for the flap vortices is $9 b_{0}$, were $b_{0}$ is the initial separation distance of the rolled up vortices. At a freestream velocity of $U=16.2 \mathrm{~m} / \mathrm{s}$ the resulting forcing frequency would be $f=U /\left(9 b_{0}\right)=1.61 \mathrm{~Hz}$. At these low frequencies, the electric motor used to drive the cam rotated nonuniformly and hence high-fidelity phase-locked vortex measurements could not be made. The frequencies considered here are higher corresponding to shorter wavelength instabilities which are growing faster, such as the Crouch instability. The difference between Crow and Crouch instability is discussed in Crouch et al. (2001) Essentially the Crouch instability leaves the vorticity centroid of the wing unperturbed while to excite the Crow instability the vorticity centroid is perturbed. With active Gurney flaps deployed on both inboard and outboard edges of the flap, both scenarios are realizable (see Greenblatt, 2005, 2007).

Table 4: Forcing frequencies, corresponding wavelengths and the phase shift considered at a velocity of $\mathrm{U}=16.2 \mathrm{~m} / \mathrm{s}$.

\begin{tabular}{|c||c|c|c|}
\hline $\mathrm{f}$ & $2.5 \mathrm{~Hz}$ & $5.0 \mathrm{~Hz}$ & $10 \mathrm{~Hz}$ \\
\hline$/ \mathrm{b}$ & 2.89 & 1.45 & 0.72 \\
\hline$(\mathrm{x} / \mathrm{c}=4)$ & $75^{\circ}$ & $150^{\circ}$ & $300^{\circ}$ \\
\hline$(\mathrm{x} / \mathrm{c}=9)$ & $214.7^{\circ}$ & $69.4^{\circ}$ & $138.9^{\circ}$ \\
\hline
\end{tabular}

A detailed study was undertaken for the $f=5 \mathrm{~Hz}$ case $(/ \mathrm{b}=2.89)$, where the PIV system was triggered at 8 phases. Gurney flap deflection angle ( $\mathrm{G}$ ) relates to phase angle ( ) according to $\mathrm{G}=90 \mathrm{sin}(\mathrm{2})$. Maximum centroid shift for each case is summarized in table 5 . Consistent with the static test, the shift in the $\mathrm{z}$ direction is reduced with downstream distance, whereas shift in y direction (spanwise) is increased. At $x / c=4$ centroid perturbations obtained by means of dynamic Gurney flaps are larger than in the static case. In case of the $x / c=9$ position this holds true for the $z$ direction only, $y$ being in the order of the static case. There is no clear dependence of perturbation amplitude on forcing frequency. Therefore perturbing the vortices at wavelengths smaller than or greater than the wingspan does not materially change the vortex centroid authority. 
Table 5. Centroid excursions when employing the active Gurney flap at different wavelengths with $\mathrm{I}_{G}=30 \%$.

\begin{tabular}{|c|c|c||c|c||c|c|}
\cline { 3 - 6 } \multicolumn{1}{c|}{} & \multicolumn{2}{c||}{$\mathrm{x} / \mathrm{c}=4$} & \multicolumn{2}{c|}{$\mathrm{x} / \mathrm{c}=9$} \\
\cline { 2 - 7 } \multicolumn{1}{c|}{} & $\mathrm{f}(\mathrm{Hz})$ & $\mathrm{b}$ & $\mathrm{y} / \mathrm{b}_{\mathrm{s}}$ & $\mathrm{z} / \mathrm{b}_{\mathrm{s}}$ & $\mathrm{y} / \mathrm{b}_{\mathrm{s}}$ & $\mathrm{z} / \mathrm{b}_{\mathrm{s}}$ \\
\hline \multirow{4}{*}{$\mathrm{h}_{\mathrm{G}}=2 \%$} & static & & 1.61 & 2.59 & 3.64 & 0.26 \\
& 2.5 & 2.89 & 2.20 & 3.40 & 3.49 & 0.89 \\
& 5.0 & 1.45 & 2.58 & 3.24 & 3.40 & 0.97 \\
& 10.0 & 0.72 & 2.10 & 3.52 & 3.44 & 1.87 \\
\hline $\mathrm{h}_{\mathrm{G}}=4 \%$ & 5.0 & 1.45 & 2.50 & 3.15 & 3.86 & 0.57 \\
\hline
\end{tabular}

The vortex centroid trajectories are plotted as a function of Gurney flap deflection $\left(0^{\circ} \quad 360^{\circ}\right)$ for all the dynamic cases in figures 13 to 16. In the paper of Vey et al (2008), peak vorticity ( $x$,max) was color encoded in the plots to reflect the local changes in aerodynamic loads, i.e. changes in shed vorticity as the Gurney flap oscillates through the cycle. Mutually perpendicular centroid shifts in y and $z$ directions were projected onto the corresponding axes and the static centroid locations were indicated for comparison. In figs. 13 to 16, a "virtual lens" has been used to add depth to the image so the vortex tube is not a simple projection onto the plane of viewing, but also a deformation due to the lens effect. Moreover the vortex movement in $y$ and $z$ directions has been magnified to clearly show the effect of active Gurney flaps. A surprising observation that was made for all cases, including the baseline and control cases, was that the flap-edge vortex strength deceased in the downstream direction. The tip vortex strength, on the other hand, did not diminish as far downstream as $x / c=22(x / b=4.5)$. In fact, for $x / c>9$ the flap-edge vortex strength dropped dramatically and could not be detected with a matrix of tufts. Additionally, smoke introduced from the edge of the flap indicated what appeared to be vortex breakdown at approximately $x / c=15$, although this was not verified by measurements; retrospectively, a simple total head probe could have been used to establish the existence of a stagnation point. This observation was counterintuitive and not in keeping with data acquired on wind tunnel models and full-scale airliners; vortex strength generally increases as more of the shed vorticity is rolled up. The main reason for vortex breakdown appeared to be the combination of large flap deflection $\left(32^{\circ}\right)$ together with a highly swept trailing-edge $(=30)$. Vortex breakdown has been observed on unswept flap edges with very large flap deflections, but this usually occurs in the vicinity of the flap-edge and not several chordlengths downstream as in the present case. In this regard it is important to note that the present model does not have the planform of a conventional airliner. Rather, both the leading- and trailing-edges are swept at a constant $30^{\circ}$ along the entire span. The original design incorporated a full-span flap; this was shortened here for the express purpose of the present study. This unique setup may serve as a vehicle for studying the enigmatic vortex breakdown or bursting phenomena.
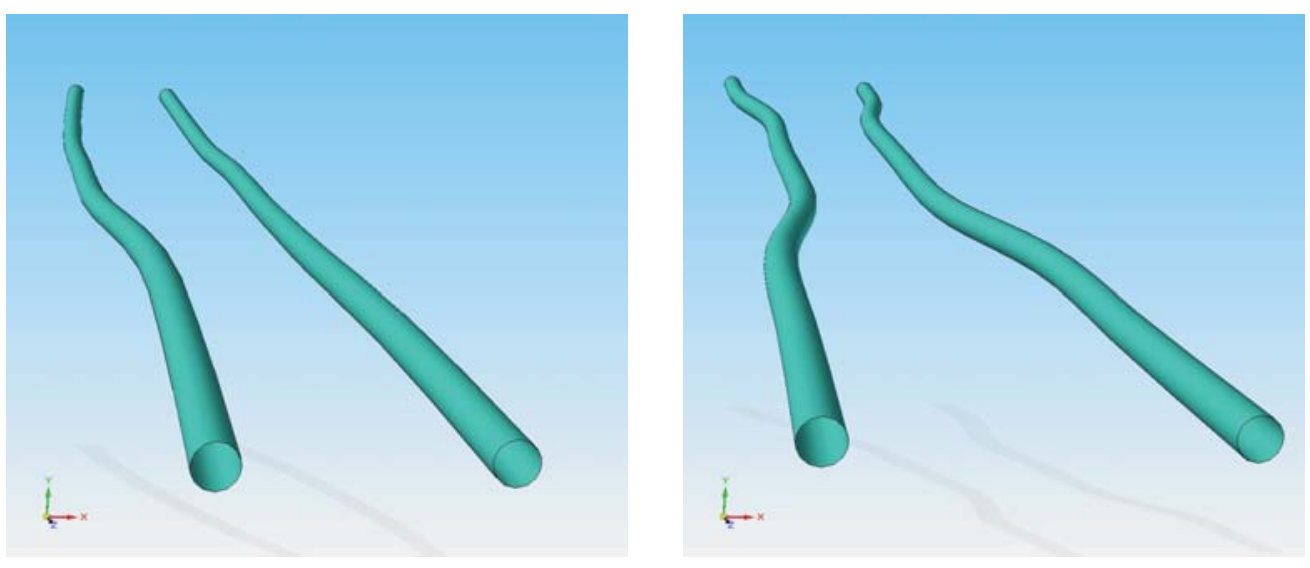

Fig. 13. Vortex trajectories as a function of phase for $h_{G}=2 \%, f=2.5 \mathrm{~Hz}, \quad / b=2.89$. Vortex trajectories at: a) $\mathrm{x} / \mathrm{c}=4 \mathrm{~b}) \mathrm{x} / \mathrm{c}=9$. 


\section{$4^{\text {th }}$ Flow Control Conference, Seattle, Washington, June 23-26, 2008}
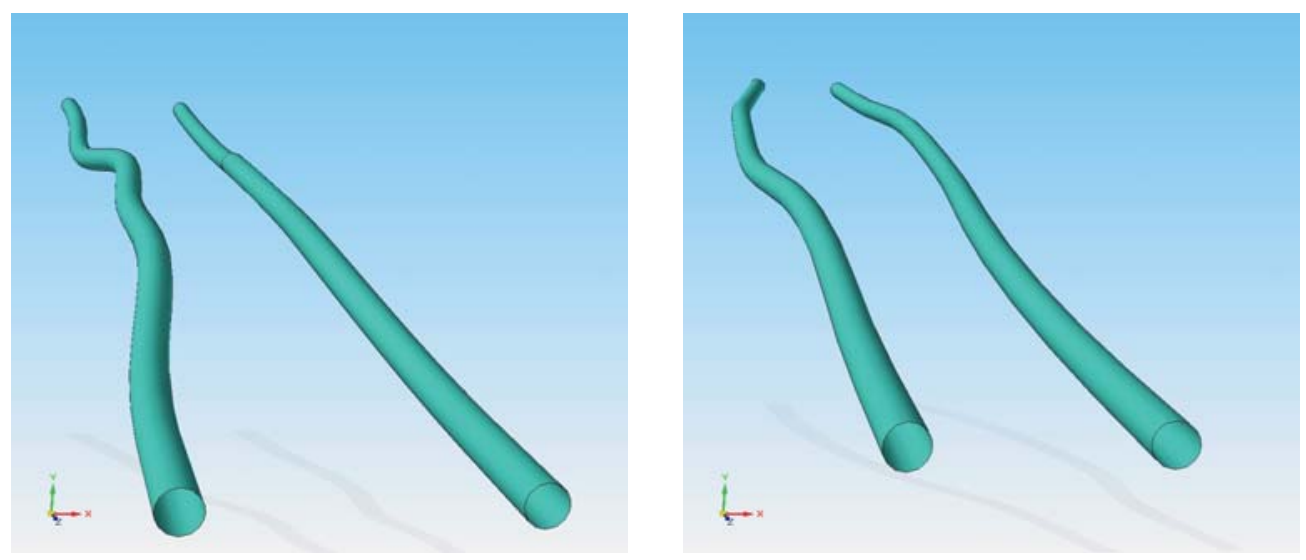

Fig. 14. Vortex trajectories as a function of phase for $h_{G}=2 \%, f=5 H z, / b=1.45$. Vortex trajectories at: $\left.a\right) x / c=4$ b) $\mathrm{X} / \mathrm{C}=9$.
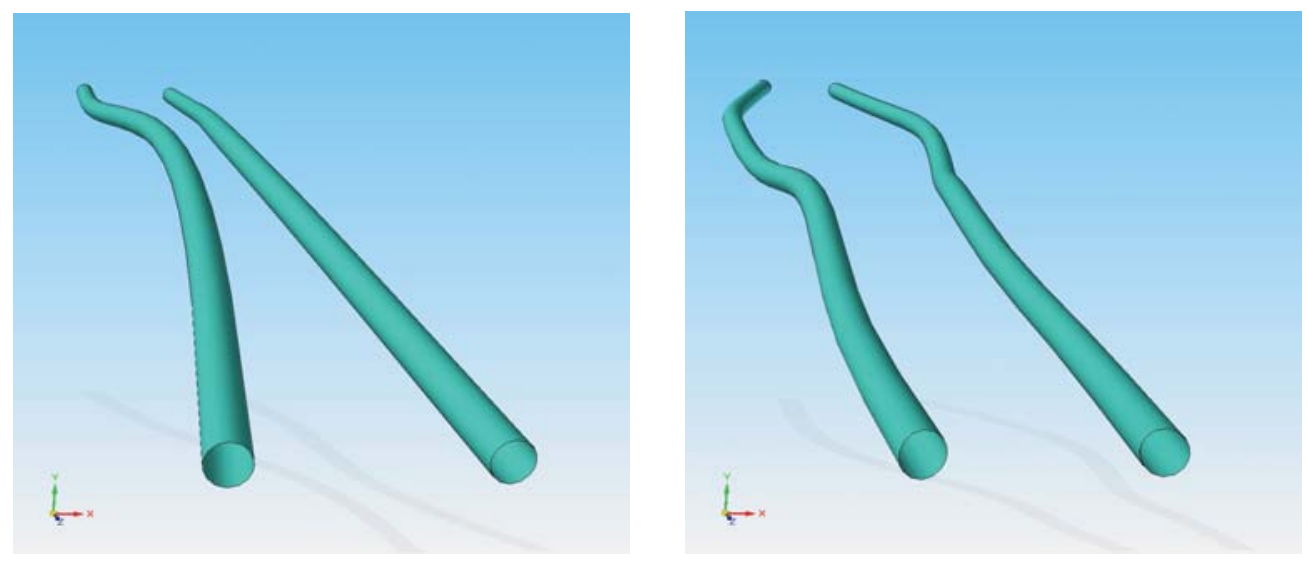

Fig. 15. Vortex trajectories as a function of phase for $h_{G}=4 \%, f=5 H z, \quad / b=1.45$. Vortex trajectories at: $\left.a\right) x / c=4$ b) $\mathrm{x} / \mathrm{c}=9$.
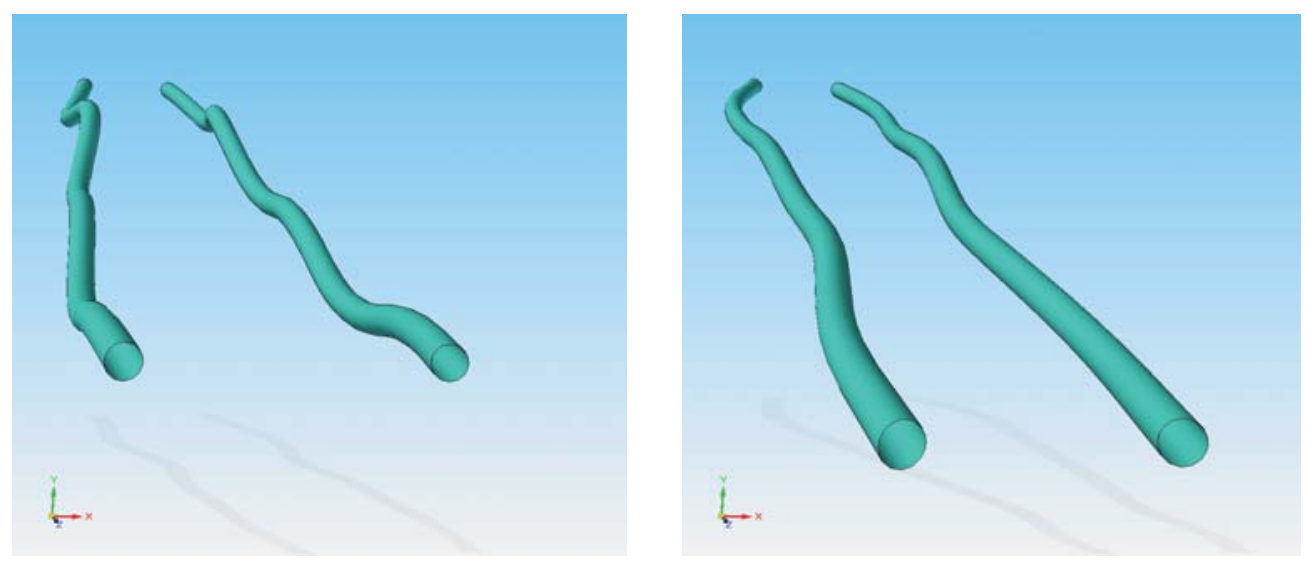

Fig. 16. Vortex trajectories as a function of phase for $h_{G}=2 \%, f=10 H z, \quad / b=0.72$. Vortex trajectories at: a) $\mathrm{x} / \mathrm{c}=4 \mathrm{~b}) \mathrm{x} / \mathrm{c}=9$. 
D. Comparison of Different Methods

In this section the present data are compared to the results of other research known to the authors. To account for the different aspect ratio semispan wings $\left(A R_{s}\right)$ used in the various investigations, the maximum attained perturbation of the vortex centroids is presented in terms of $y / b_{s}$ as well as $y / b_{s} \times A R_{s}$; the latter term is equivalent to $y / \bar{c}$. The data presented in table 6 was taken in the near field of the wake at various comparable downstream positions. A truly meaningful comparison would require different control mechanisms to be applied to one and the same model, with measurements at the same downstream location under identical conditions. Nevertheless, the comparison presented here provides insight into the various techniques.

Wing tip vortex control by static Gurney flaps was addressed by Matalanis \& Eaton (2007a). They equipped the wing of a half span model with so-called miniature trailing edge effectors (MiTEs) of $h_{G}=1.5 \%$. Their experiments were conducted on a semispan NACA $0012(A R=4.1)$ at $=8.9$ and $R e=350,000$. The wing comprised with Gurney flaps deployed on large fractions of span were found to predominately control the vortex in the direction of lift, whereas Gurney flaps deployed over a small fraction of the span shifted the vortex both in spanwise and lift direction. This observation is full consistent with Betz's hypothesis. In their study the measurement plane was placed at $\mathrm{x} / \mathrm{C}=4.9$ downstream of the wing. They also concluded that actively deployable MiTEs may be used for wake alleviation. In a more recent paper by the same authors (Matalanis \& Eaton, 2007b) the tip vortex of the same model was controlled by rapidly actuated Gurney flaps. Computational simulations by the authors showed that MiTEs are capable of exciting instabilities in four vortex configurations thus concluding that a reduction in aircraft spacing rules would be possible. The effect of Gurney flaps on wing tip vortices was also addressed by Nikolic (2006) who found that the addition of Gurney flaps alters the near field roll-up pattern of a wing tip vortex. He visualized the vortex structure with tufts, and found that tip vortex "strength" decreased with increasing Gurney flap height. This is in contrast to theory because Gurney flaps increase the local circulation and therefore vortex strength should be increasing with growing Gurney flap height. The apparent reduction in vortex strength was probably due to the wake shed by the Gurney flaps (Meyer et al, 2006) which is rolled up into the vortex, rendering it more diffuse.

Table 6. Comparison of maximum lateral centroid perturbation for different investigations.

\begin{tabular}{|c|c|c|c|c|c|c|}
\hline Researcher & Wing/Profile type & Investigation type & $y / b_{s}$ & $\mathrm{y} / \mathrm{b}_{\mathrm{s}} A \mathrm{R}_{\mathrm{s}}$ & Re range & $\begin{array}{c}\text { Meas. } \\
\mathrm{x} / \mathrm{c}\end{array}$ \\
\hline $\begin{array}{c}\text { Matalanis \& } \\
\text { Eaton }(2007 a, b)\end{array}$ & NACA 0012 & $\begin{array}{c}\text { Gurney Flaps of } \\
\mathrm{h}_{\mathrm{G}}=1.5 \% \text { at the wingtip }\end{array}$ & $2.05 \%$ & $4.10 \%$ & 350,000 & 4.9 \\
\hline Coustols (2004) & $\begin{array}{c}\text { Very large } \\
\text { transport aircraft } \\
\text { half-model }\end{array}$ & $\begin{array}{l}\text { Continuous and pulsed } \\
\text { blowing at the wing tip }\end{array}$ & $\sim 0.42 \%$ & $\sim 1.9 \%$ & $\begin{array}{l}450,000 \\
750,000\end{array}$ & 1 \\
\hline $\begin{array}{l}\text { Greenblatt } \\
\text { (2005) }\end{array}$ & $\begin{array}{c}\text { Passive and active } \\
\text { flap separation } \\
\text { control }\end{array}$ & $\begin{array}{l}\text { Passive and active flap } \\
\text { separation control }\end{array}$ & $2.70 \%$ & $5.4 \%$ & $\begin{array}{c}500,000 \\
\text { to } 10^{6}\end{array}$ & 2 \\
\hline $\begin{array}{l}\text { Greenblatt et al } \\
(2006)\end{array}$ & $\begin{array}{c}\text { Passive and active } \\
\text { tip-flap separation } \\
\text { control }\end{array}$ & $\begin{array}{l}\text { Passive and active flap } \\
\text { separation control }\end{array}$ & $\begin{array}{l}1.4 \% \\
2.2 \%\end{array}$ & $\begin{array}{l}2.8 \% \\
4.4 \%\end{array}$ & $\begin{array}{c}500,000 \\
\text { to } 10^{6}\end{array}$ & $\begin{array}{l}2.2 \\
7.2\end{array}$ \\
\hline \multirow{4}{*}{ Vey et al (2008) } & \multirow{4}{*}{$\begin{array}{l}\text { Swept constant- } \\
\text { chord half-model }\end{array}$} & $\begin{array}{c}\text { Gurney flap } h_{G}=2 \% \text {, } \\
I_{G}=30 \% \text { at the flap edge }\end{array}$ & $2.58 \%$ & $6.42 \%$ & \multirow{4}{*}{$\begin{array}{l}500,000 \\
700,000\end{array}$} & 4 \\
\hline & & $\begin{array}{c}\text { Gurney flap } h_{G}=4 \% \text {, } \\
I_{G}=30 \% \text { at the flap edge }\end{array}$ & $2.8 \%$ & $6.94 \%$ & & 4 \\
\hline & & $\begin{array}{c}\text { Gurney flap } h_{G}=2 \% \text {, } \\
I_{G}=40 \% \text { at the flap edge }\end{array}$ & $4.10 \%$ & $10.17 \%$ & & 9 \\
\hline & & $\begin{array}{l}\text { Gurney flap } \mathrm{h}_{\mathrm{G}}=4 \% \text {, } \\
\mathrm{I}_{\mathrm{G}}=40 \% \text { at the flap edge }\end{array}$ & $5.30 \%$ & $13.14 \%$ & & 9 \\
\hline
\end{tabular}


Finally, Coustols et al. (2004) of ONERA influenced the wing tip vortex of a very large transport aircraft (VLTA) half-model at 450,000 Re 750,000 by continuous and pulsed blowing at the wing tip. Their work was also aimed at exciting instabilities in the trailing vortex system. Apart from active control techniques Coustols et al investigated differential flap settings to create a multiple vortex system with enhanced decay characteristics. It is not clear if any of these methods are amenable to retrofitting on existing aircraft.

It is evident from table 6 that, in general, control at the flap edge produces larger vortex perturbations than control at the wingtip. Based on the Donaldson-Betz hypothesis, the main reason for this is because the vortex rolls up from $|d / d y|_{\max }$ : in the case of the wingtip theoretically this is at $y=b_{s}$ where $d / d y \quad$; in the case of the flapedge region this is at the span-loading inflection point. Thus it is much more difficult to perturb the wingtip vortex theoretically as small changes to large $\mathrm{d}$ /dy will not produce a strong effect. In contrast, in the vicinity of the flapedges $|\mathrm{d} / \mathrm{dy}|_{\max }$ is finite and this finite peak must be displaced along the span in order to perturb the vortex in spanwise direction. This is seen by comparing separation control on inboard and tip flaps (cf. Greenblatt, 2005 and Greenblatt et al, 2006) where the perturbation is nearly twice as large in the former case. A similar conclusion can be drawn by comparing Matalanis \& Eaton $(2007 a, b)$ and Vey et al (2008). More evidence for this hypothesis is provided by jet blowing into the vortex core, which does not fundamentally alter the span loading i.e. the vortex sheet from which the vortex rolls up. This might be the reason for the small centroid shifts compared to the other techniques.

Despite the limitations in progress of the present investigations, the data presented herein and the comparison shown in table 6 clearly shows the potential of Gurney flaps for wake vortex management, and potentially for vortex alleviation. To the best knowledge of the authors of this paper, flap edge vortex alleviation using Gurney flaps has not been applied in the past. Nevertheless, there are projects with the potential to test the method (e.g Hansen, 2003), where deployable Gurney flaps can be employed on the flaps.

\section{Conclusions}

The series of investigations performed initially at NASA Langley Research Center and then subsequently at the Berlin University of Technology in collaboration with the German Aerospace Center, have demonstrated the basic mechanism for managing trailing vortices using retrofitted devices that are decoupled from the conventional control surfaces. The basic premise for managing vortices is rooted in the method of Betz, as extended to flaps by Donaldson and his colleagues. Using these devices, vortices may be perturbed at arbitrarily long wavelengths down to wavelengths less than a typical airliner wingspan and the oscillatory loads on the wings, and hence the vehicle, are small. Significant flexibility in the specific device has been demonstrated using local passive and active separation control as well as local circulation control via Gurney flaps. Clearly, a combination of devices can be used, such as vortex generators, and Gurney flaps: the former are used on conventional high-lift systems (e.g. Nield, 1995) and the latter on experimental aircraft (e.g. Hansen, 2003). For application to a wake vortex alleviation scheme, these "passive" devices must be driven in a time-dependent manner.

The method is now in a position to be tested in a wind tunnel with a longer test section on a scaled airliner configuration. Alternatively, the method can be tested directly in a towing tank, on a model aircraft, a light aircraft or a full-scale airliner. The authors believed that this method will have significant appeal from an industry perspective due its retrofit potential with little to no impact on cruise (devices tucked away in the cove or retracted); low operating power requirements; small lift oscillations when deployed in a dynamic manner; and significant flexibility with respect to the specific devices selected.

\section{Acknowledgements}

Parts of this work were performed while the first author held a National Research Council-NASA Langley Research Center Associateship. In this regard, the first author acknowledges W. L. Sellers III, A. E Washburn, L. P. Melton, and L. N. Jenkins. At the Berlin University of Technology the authors would like to acknowledge the support of H. Stolpe, R. Nagel and W. Hage.

\section{References}

1. Bellastrada, C., Breitsamter, C. and Laschka, B, "Investigation of Turbulent Wake Vortex Originating From a Large Transport Aircraft in Landing Configuration," Proc. CEAS Aerospace Aerodynamics Research Conference, 2002, pp 31.1-31.10.

2. Betz, A., "Behavior of Vortex Systems," Zeit. für angewandte Math. und Mech., Vol. 12, No. 3, June 1932. See NACA TM 713, June 1933. 
3. Bilanin, A. J., and Widnall, S. E., "Aircraft Wake Dissipation by Sinusoidal Instability and Vortex Breakdown," AIAA Paper 73-107, 1973.

4. Brion, V.D. Sipp, and L. Jacquin. Optimal amplification of the Crow instability, submitted to Phys. Fluids (2007).

5. Broderick, A.J. et al, "Wake turbulence, an obstacle to increased air traffic capacity," Committee to Conduct an Independent Assessment of the Nation's Wake Turbulence Research and Developmental Program, National Research Council, ISBN: 0-309-11380-6, www.nap.edu/catalog/12044.html, Accessed April 2008.

6. Cliffone, D. L. and Orloff, K. L., "Far Field Wake-Vortex Characteristics of Wings," AIAA Journal of Aircraft, Vol. 12, No. 5, 1975, pp. 464-470.

7. Coustols, E., Jacquin, L., Moens, F., Molton, P., "Status of ONERA Research on Wake Vortex in the Framework of National Activities, European Congress on Computational Methods in Applied Sciences and Engineering (ECCOMAS)," 2004.

8. Crouch, J. D., "Forcing the Breakup of Airplane Trailing Vortices," Conference on Capacity and Wake Vortices, Imperial College of Science, Technology and Medicine, London, England, September 2001.

9. Crouch, J.D. 2005. Airplane trailing vortices and their control. Comptes Rendus Physique. 6:487-499.

10. Crouch, J.D., G.D. Miller, and P.R. Spalart. 2001. Active-control system for breakup of airplane trailing vortices. AIAA Journal 39:2374-2381.

11. Crow, S., "Stability theory for a pair of trailing vortices," AIAA Journal, Vol. 8, 1970, pp. 2172-2179.

12. Crow, S. C., "Panel Discussion," in Aircraft Wake Turbulence and Its Detection, edited by J. H. Olsen, A., Goldburg, and M. Rogers, 1971, Plenum Press, New York, pp. 580-582.

13. Crow, S. C. and Bate E. R., "Lifespan of Trailing Vortices in a Turbulent Atmosphere," Journal of Aircraft, Vol. 13, No 7, 1976, pp. 476-82.

14. de Bruin, A.C., Hegen, S.H., Rohne, P.B. and Spalart, P.R., "Flow Field Survey in the Trailing Vortex System Behind a Civil Aircraft Model at High Lift," AGARD-CP-584, 1996, pp. 25-1 to 25.12.

15. Donaldson, C duP., Snedeker, R. S. and Sullivan, R. D., "Calculation of Aircraft Wake Velocity Profiles and Comparison with Experimental Measurements," AIAA Journal of Aircraft, Vol. 11, No. 9, 1974, pp. 547-555.

16. Durston, D.A., S.M. Walker, D.M. Driver, S.C. Smith, and O. Sava . 2005. Wake-vortex alleviation flowfield studies. Journal of Aircraft 42:894-907.

17. Fabre, D., Jacquin, L. and Loof. A., "Optimal perturbations in a four-vortex aircraft wake in counterrotating configuration. Journal of Fluid Mechanics, 2002, 451:319-328.

18. Fine, N.E. and Kring, D.C., "Opto-Acoustic Tracking of Aircraft Wake Vortices," AIAA Paper 2005-2965, 11th AIAA/CEAS Aeroacoustics Conference, 26th AIAA Aeroacoustics Conference, May 23-25, 2005, Monterey, CA.

19. Frech, M. and Holzäpfel, F., "Skill of an Aircraft Wake-Vortex Model Using Weather Prediction and Observation," AIAA Journal of Aircraft, Vol. 45, No. 2, March-April 2008, pp. 461-470.

20. Greenblatt, D., "Managing Flap Vortices via Separation Control," AIAA Journal, Vol. 44, No. 11, 2006, pp. 27552764.

21. Greenblatt, D., "Management of Vortices Tailing Flapped Wings via Separation Control," AIAA Paper 2005-0061, 43rd AIAA Aerospace Sciences Meeting and Exhibit, Reno, Jan. 2005.

22. Greenblatt, D., Melton, L., Yao, C., Harris, J., "Control of a Wing Tip Vortex" AIAA Paper 2005-4851, 23rd AIAA Applied Aerodynamics Conference, Westin Harbour Castle, Toronto, Ontario, 6-9 June 2005.

23. Hansen, H., Application of Mini-Trailing-Edge Devices in the AWIATOR Project, Airbus Deutschland EGAG, Bremen, 2003. (also see www.awiator.net, accessed 13. August 2007.)

24. Haverkamp, S., Neuwerth, G. Jacob, D., "Active and passive vortex wake mitigation using control surfaces," Aerospace Science and Technology, Volume 9, Issue 1, January 2005, Pages 5-18.

25. Kingsley-Jones, M., "Boeing 747-8 vs A380: A titanic tussle," FlightInterational.com, 14 February 2006.

26. Li, Y., Wang, J., and Zhang, P., Influences of Mounting Angles and Locations on the Effects of Gurney Flaps, Journal of Aircraft, Vol. 40, No. 3, 2003, pp. 494-498.

27. Matalanis, C.G., Eaton, J.E., Wake Vortex Control Using Static Segmented Gurney Flaps, AIAA Journal, Vol. 45, No. 2, 2007a, pp. 321-328.

28. Matalanis, C.G., Eaton, J.E., Wake Vortex Alleviation Using Rapidly Actuated Segmented Gurney Flaps, AIAA Journal, Vol. 45, No. 8, 2007b.

29. Meyer, R. et. al., Drag Reduction on Gurney Flaps by Three-Dimensional Modifications, Journal of Aircraft, Vol. 43, No. 1, 2006, pp. 132-140.

30. Michel, U. and P. Böhning, "Investigation of Aircraft Wake Vortices with Phase Microphone Arrays," AIAA Paper 2002-2501, 2002.

31. Nield, B. N., "An overview of the Boeing 777 high lift aerodynamic design," Aeronautical Journal," Nov. 1995. pp. 361-371.

32. Nikolic, V.R., Effect of Full-Span Gurney Flap Height on Wing Wake Vortex Alleviation, Journal of Aircraft, Vol. 43, No. 5, 2006, pp. 1555-1558.

33. Ortega, J. M., Bristol R. L. and Savas, O.., "Experimental Study of the Instability of Unequal-Strength Counter-Rotating Vortex Pairs" J. Fluid Mech., Vol. 474, 2003, pp. 35-84.

34. Pradeep, D.S., and F. Hussain. 2006. Transient growth of perturbations in a vortex column. Journal of Fluid Mechanics 550:251-288. 
35. Rennich, S. C. and Lele, S. K., "Method for Accelerating the Destruction of Aircraft Wake Vortices," AIAA Journal of Aircraft, Vol. 36, No. 2, 1999, pp. 398-404.

36. Rossow, V. J. "Theoretical Study of Lift-Generated Vortex Wakes Designed to Avoid Rollup," AIAA Journal, Vol. 13 No. 4, 1975, pp. 476-484.

37. Rossow V. J. "Lift-Generated Vortex Wakes of Subsonic Transport Aircraft," Progress in Aerospace Sciences, Volume 35, Issue 6, 1999, pp. 507-660.

38. Sava , O. 2005. Experimental investigations on wake vortices and their alleviation. Comptes Rendus Physique, Vol. 6, pp. 415-429.

39. Schmitt, N. P., Rehm, W., Pistner, T., Zeller, P., Diehl, H. and Navé, P., “The AWIATOR airborne LID AR turbulence sensor," Aerospace Science and Technology, Vol. 11, 2007, pp. 546-552.

40. Spalart, P. R., "Airplane Trailing Vortices," Annual Review of Fluid Mechanics, Vol. 30, 1998, pp. 107-138.

41. Vey, S., Greenblatt, D. Paschereit, C.O. and Meyer, R., "Flap Vortex Management by Active Gurney Flaps," AIAA Paper 2008-286, 46th AIAA Aerospace Sciences Meeting and Exhibit, 7-10 January 2008, Reno NV.

42. Williamson, C. H. K, Leweke, T. and Miller, G. D., "Fundamental instabilities in spatially-developing wing wakes and temporally-developing vortex pairs", Proceedings of FEDSM '98, 1998 ASME Fluids Engineering Division Summer Meeting, June 21-25, 1998, Washington DC. 